\title{
EXPLORING THE INTERFACE
}

\section{Explicit Focus-on-Form Instruction and Learned Attentional Biases in L2 Latin}

\author{
Myrna Cintrón-Valentín and Nick C. Ellis \\ University of Michigan
}

Eye-tracking was used to investigate the attentional processes whereby different types of focus on form (FonF) instruction assist learners in overcoming learned attention and blocking effects in their online processing of second language input. English native speakers viewed Latin utterances combining lexical and morphological cues to temporality under control conditions and three types of explicit FonF: verb grammar instruction, verb salience with textual enhancement, and verb pretraining. Chinese native speakers were also tested on control and verb grammar conditions. All groups participated in three phases: exposure, comprehension test, and production test. Verb grammar participants viewed a short lesson on Latin tense morphology prior to exposure. Verb salience participants saw the verb inflections highlighted in bold and red during exposure. Verb pretraining participants took part in an additional introductory phase in which they were presented with solitary verb forms and were trained on their English translations. Instructed participants showed greater sensitivity to morphological cues in comprehension and production. Eye-tracking revealed how FonF affects learners' attention during online processing and thus modulates long-term blocking of verb morphology.

This research was supported by National Science Foundation Grant BCS-0717557. We thank Fatemeh Abdollahi, Kausar Hafeez, Katherine Martin, Tony Natoci, and Yiran Xu for helping design, pilot, score, and administer parts of these experiments.

Correspondence concerning this article should be addressed to Myrna Cintrón-Valentín, Department of Psychology, 530 Church Street, Ann Arbor, MI 48109. E-mail: mcintron@ umich.edu 
Naturalistic second language (L2) learners tend to focus more on openclass words (nouns, verbs, adjectives, and adverbs) than on grammatical cues in their language processing. Grammatical morphemes and closedclass words tend not to be put to full use (e.g., Bardovi-Harlig, 1992; Clahsen \& Felser, 2006; Schmidt, 1984; VanPatten, 1996, 2006). So L2 learners initially make temporal references mostly by use of temporal adverbs, prepositional phrases, serialization, and calendric reference, with the grammatical expression of tense and aspect emerging only slowly thereafter, if at all (Bardovi-Harlig, 1992, 2000; J. F. Lee, 2002; Meisel, 1987; Noyau, Klein, \& Dietrich, 1995).

One might ask whether this failure to learn L2 morphology, which can take place even after many years of rich L2 experience (Klein, 1998; Schmidt, 1984), reflects a failure of explicit learning or a failure of implicit learning. The answer must be both. For these nonlearners, neither implicit learning nor explicit learning has produced observable gains in acquisition over thousands of experiences of tense morphology from untutored naturalistic usage. In the sections that follow, we address the questions of how to promote the learning of these constructions; whether such learning can be promoted by exploiting explicit learning, implicit learning, or both; and whether these two forms of knowledge can influence each other. Issues of the interface of explicit and implicit knowledge are central to SLA research and practice (N. C. Ellis, 2005).

\section{BACKGROUND}

\section{Salience and Learned Attention}

One factor determining cue selection is salience: Prepositional phrases, temporal adverbs, and other lexical cues to time are salient and stressed in the speech stream. Verb inflections are not (consider yesterday I walked). The low salience and low reliability of grammatical cues tends to make them less learnable (N. C. Ellis, 2006b; Goldschneider \& DeKeyser, 2001). N. C. Ellis (2006a, 2006b) attributes L2 difficulties in acquiring inflectional morphology to an effect of learned attention known as blocking (Kamin, 1969; Kruschke, 2006; Kruschke \& Blair, 2000; Mackintosh, 1975). Blocking is an associative learning phenomenon, occurring in animals and humans alike, that shifts learners' attention to input as a result of prior experience (Rescorla \& Wagner, 1972; Shanks, 1995; Wills, 2005). Knowing that a particular stimulus is associated with a particular outcome makes it harder to learn that another cue (also associated with that particular outcome) is a good predictor of the same outcome. The prior association "blocks" further associations.

There are many situations in L2 acquisition in which cues are redundant (Schmidt, 2001; Terrell, 1991; VanPatten, 1996) and thus, as a consequence 
of blocking, may be less readily learned. Where a learner's first language (L1) experience has led him or her to look elsewhere for cues to interpretation, he or she may use these types of cues where available in the L2. For example, L1-derived knowledge that there are reliable lexical cues to temporal reference (words like gestern in German, hier in French, ayer in Spanish, and yesterday in English) may block the acquisition of verb tense morphology from analysis of utterances such as Yesterday I walked.

A number of theories of SLA incorporate related notions of transfer and learned attention. The competition model (MacWhinney, 2001; MacWhinney \& Bates, 1989; MacWhinney, Bates, \& Kliegl, 1984) was explicitly formulated to deal with competition between multiple linguistic cues to interpretation. Input processing theory (VanPatten, 1996) includes a lexical preference principle, which states that "learners will process lexical items for meaning before grammatical forms when both encode the same semantic information" (VanPatten, 2006, p. 118), and a preference for nonredundancy principle, which states that "learners are more likely to process nonredundant meaningful grammatical markers before they process redundant meaningful markers" (VanPatten, 2006, p. 119). Benati (2013) reviews a series of studies that show that learners are better able to identify temporal reference when presented with temporal adverbs rather than verbal morphological cues.

\section{Prior Experiments on Learned Attention and Blocking}

N. C. Ellis, Sagarra, and colleagues (N. C. Ellis et al., 2014; N. C. Ellis \& Sagarra, 2010a, 2011) report a series of experimental investigations of learned attention in L2 acquisition involving the learning of a small number of Latin expressions and their English translations. We describe these studies in some detail here because they introduce key concepts and because we build on their design in the present study.

In N. C. Ellis and Sagarra (2011) there were three groups: adverb pretraining, verb pretraining, and control. In Phase 1, adverb pretraining participants learned two adverbs and their temporal reference: hodie "today" and heri "yesterday"; verb pretraining participants learned verbs (shown in either first, second, or third person) and their temporal reference (e.g., cogito "think" [present] or cogitavisti "thought" [past]); and the control group had no such pretraining. In Phase 2, all participants were shown sentences that appropriately combined an adverb and a verb (e.g., heri cogitavi "yesterday I thought," hodie cogitas "today you think," cras cogitabis "tomorrow you will think") and learned whether these sentences referred to the past, the present, or the future. In Phase 3, the reception test, all combinations of adverb and verb tense 
marking were presented individually, and participants were asked to judge whether each sentence referred to the past, present, or future. The logic of the design was that in Phase 2 every utterance contained two temporal references - an adverb and a verb inflection. If participants paid equal attention to these two cues, then in Phase 3 their judgments would be equally affected by them. If, however, they paid more attention to adverb (or verb) cues, then their judgments would be swayed toward them in Phase 3.

The results showed that the three groups reacted to the cues in very different ways: The adverb pretraining group followed the adverb cue, the verb pretraining group tended to follow the verb cue, and the control group lay in between. N. C. Ellis and Sagarra (2011) report multiple regression analyses, one for each group, in which the dependent variable was the group mean temporal interpretation for each of the Phase 3 strings, and the independent variables were the information conveyed by the adverbial and verbal inflection cues; in standardized $B$ coefficients: adverb group time $=0.99$ adverb -0.01 verb; verb group time $=0.76 \mathrm{adverb}+0.60 \mathrm{verb} ;$ and control group time $=0.93 \mathrm{adverb}+$ 0.17 verb.

N. C. Ellis and Sagarra (2010a) Experiment 2 and N. C. Ellis and Sagarra (2011) Experiments 2 and 3 also illustrated long-term language transfer effects whereby the nature of learners' L1 (+/- verb tense morphology) biased the acquisition of morphological versus lexical cues to temporal reference in the same subset of Latin. First language speakers of Chinese (no tense morphology) were less able than L1 speakers of Spanish or Russian (rich morphology) to acquire inflectional cues from the same language experience in which adverbial and verbal cues were equally available (learned attention to tense morphology in standardized $\beta$ coefficients): Chinese $(\beta=-0.02)<$ English $(\beta=0.17)<$ Russian $(\beta=0.22)$ $<$ Spanish $(\beta=0.41 ;$ N. C. Ellis \& Sagarra, 2011, Table 4). These findings suggest that there is long-term attention to language, a processing bias affecting subsequent cue learning that comes from a lifetime of prior L1 usage.

Such experiments demonstrate both short-term and long-term effects in which sensitivity to lexical cues blocks subsequent acquisition of inflectional morphology. These learned attention effects have elements of both positive and negative transfer. Prior use of adverbial cues causes participants to pay more attention to adverbs; that is, there are positive effects of entrenchment of the practiced cue (see N. C. Ellis, 2002, for a review of frequency effects). Additionally, increased sensitivity to adverb cues is accompanied by a reduced sensitivity to morphological cues (i.e., blocking). A meta-analysis of the combined results of N. C. Ellis and Sagarra (2010a, 2011) demonstrated that the average effect size of entrenchment was large $(d=1.23)$ and that of blocking was moderate $(d=-0.52)$. 


\section{Explicit Instruction: Refocusing Attention and the Explicit/Implicit Interface}

Can learned attentional biases be overcome by interventions that retune attention? Focus on form (FonF) instruction attempts to do this (Doughty \& Williams, 1998; Long, 1991). For example, processing instruction (VanPatten, 1996) aims to alter learners' default processing strategies to change the ways in which they attend to input data and, thus, to maximize the amount of intake of data in L2 acquisition. Focus on form can first help the learner to recognize relevant cues to interpretation that otherwise he or she might ignore. Conscious awareness is important in the initial consolidation of a new pattern recognition unit as an explicit, episodic memory (N. C. Ellis, 2005). These are mechanisms of Schmidt's $(1990,1993)$ noticing hypothesis, "since many features of L2 input are likely to be infrequent, non-salient, and communicatively redundant, intentionally focused attention may be a practical (though not theoretical) necessity for successful language learning" (Schmidt, 2001, p. 23).

However, knowing a cue does not necessarily entail that it will be used. Explicit knowledge and implicit knowledge are distinct and dissociated; they involve different types of representation and are substantiated in separate parts of the brain (Ellis, 1994; Rebuschat, in press). There are always possibilities of noninterface, whereby learners who can explain a grammatical rule nevertheless fail to put it to everyday use (N. C. Ellis, 1993; Krashen, 1985). Likewise, one can have relevant knowledge but fail to recall it because the processes engaged in during encoding do not match those engaged in during retrieval. Lightbown (2008) calls this a lack of "transfer appropriate processing" (p. 27). The new cue must be integrated into routine processing.

Terrell (1991) characterized explicit grammar instruction (EGI) as "the use of instructional strategies to draw the students' attention to, or focus on, form and/or structure" (p. 53), with instruction targeted at increasing the salience of inflections and other commonly ignored features by, first, pointing them out and explaining their structure and, second, providing meaningful input that contains many instances of the same grammatical meaning-form relationship. Terrell had worked with Krashen, reacting against the worst forms of traditional grammar instruction and developing the best method for an instruction-free natural approach (Krashen \& Terrell, 1983). Nevertheless, after sufficient experience with the natural approach, he proposed three ways in which EGI may affect acquisition: (a) "as an advance organizer to help the learner make sense of input," (b) "as a meaning-form focus in communication activities in which there are many examples of a single meaning-form relationship," and (c) as a way to encourage monitoring, which "itself might directly 
affect acquisition if it is possible for learners to acquire their own output" (Terrell, 1991, p. 62). He closed his article as follows:

\begin{abstract}
Naturally, the proposals in this paper are only hypotheses which will need to be confirmed or rejected in two ways: by teachers in the classroom, who will find them useful or not, and by researchers, who will look at learners with and without such instruction to see if there are predictable differences. (Terrell, 1991, p. 62)
\end{abstract}

We intend to examine learners with and without EGI in the present study.

There are several options for FonF instruction (see, e.g., the classifications in Norris \& Ortega, 2000). Attention can be redirected in various ways: Grammar instruction can make learners explicitly aware of how cues work in hopes that this knowledge will be memorable enough to encourage subsequent use of it. Textual enhancement (TE) aims to draw learners' attention to the relevant cues during processing. Cue pretraining in isolation in task-essential rather than redundant contexts is another method. The present research aims to contrast and illuminate the processes by which these different methods of FonF act in usage to counteract learned attentional biases.

\title{
Verb Grammar Instruction (VG)
}

Grammar instruction has been broadly defined as "any instructional technique that draws learners' attention to some specific grammatical form in such a way that it helps them either to understand it metalinguistically and/or process it in comprehension and/or production so that they can internalize it" (R. Ellis, 2006, p. 84). Such form-focused instruction (FFI; Spada, 1997) can be either implicit or explicit. In implicit FFI, learners are expected to infer rules without awareness, whereas explicit FFI involves either the presentation of rules or a means for the learners to inductively resolve the rule (R. Ellis, 2008). The meta-analysis of the effects of grammar instruction by Norris and Ortega (2000) showed that learners who received explicit types of L2 instruction outperformed learners who received implicit types. Likewise, the more recent metaanalysis by Spada and Tomita (2010), in which at least half the studies included free constructed-response outcome measures, found a larger advantage of explicit instruction in the acquisition of both complex and simple language forms. Nevertheless, as R. Ellis (2012, Chapter 9) makes clear in his yet more recent review of FFI, it is often difficult to compare and collate studies because explicit treatments tend to be combined with other methods, such as negative feedback and rule review, whereas implicit groups typically include only one source of exposure. 
Weighing these considerations, the operationalization of VG we adopted here was a short, hopefully clear and memorable, metalinguistic description of simple regular tense morphology in Latin. The four slides we used under computer administration are shown in Figure 1.

These meta-analyses also discuss the difficulties of comparing studies with quite different outcome measures, some much more explicit than others (as first made clear in Norris \& Ortega, 2000). In this experiment, therefore, we used the same variety of comprehension and production measures for all of our treatments.

\section{Verb Salience (VS)}

Input enhancement involves relatively unobtrusive methods to direct learners' attention to nonsalient forms in the input (Doughty \& Williams, 1998; Sharwood Smith, 1993). In TE, visual manipulations such as colorcoding, boldfacing, and underlining are typically used to enhance forms in written input and thus to prompt learners' further processing of these cues (Sharwood Smith, 1993). Research has yielded conflicting findings regarding its effectiveness. Some studies demonstrate that TE is successful in drawing learners' attention to the target forms (Alanen, 1995; Cho, 2010; Izumi, 2002; Jourdenais, Ota, Stauffer, Boyson, \& Doughty, 1995; S.-K. Lee, 2007; Winke, 2013) and in enhancing their subsequent knowledge of these forms (Jourdenais et al., 1995; S.-K. Lee,

\begin{tabular}{|c|c|c|c|c|}
\hline $\begin{array}{l}\text { In this section, you will be presented a short } \\
\text { grammar lesson on Latin verb structure. The } \\
\text { information in this lesson will help you } \\
\text { answer the questions that will appear later in } \\
\text { the experiment. You are encouraged to take } \\
\text { as much time as you like to study the lesson, } \\
\text { but be aware that once you advance to the } \\
\text { next page you will not be able to go back. }\end{array}$ & $\begin{array}{l}\text { 1. The stem, } \\
\text { 2. The tense ma } \\
\text { verb t } \\
\text { 3. The agreen } \\
\text { the ac }\end{array}$ & $\begin{array}{l}\text { arker, which t } \\
\text { akes place (pa } \\
\text { nent marker, } \\
\text { ction (first, sec }\end{array}$ & $\begin{array}{l}\text { you when } \\
\text { present, or } \\
\text { ch tells you } \\
\text {, or third }\end{array}$ & $\begin{array}{l}\text { for example, } \\
\text { action of the } \\
\text { ure) } \\
\text { ho performs } \\
\text { son) }\end{array}$ \\
\hline Breakdown of the three parts of a verb: & \multicolumn{4}{|c|}{$\begin{array}{l}4 \text { A verb can appear in any combination of past, present, or future, } \\
\text { and first, second, or third person. }\end{array}$} \\
\hline \multirow[b]{2}{*}{ STEM + TENSE MARKER + AGREEMENT MARKER } & & Past & Present & Future \\
\hline & First Person & $\begin{array}{l}\text { verbavi } \\
\text { I verbed }\end{array}$ & $\begin{array}{l}\text { verbo } \\
\text { I verb }\end{array}$ & $\begin{array}{l}\text { verbabo } \\
\text { I will verb }\end{array}$ \\
\hline Such a verb might look like this: & $\begin{array}{l}\text { Second Person } \\
\text { You }\end{array}$ & $\begin{array}{l}\text { verbavisti } \\
\text { You verbed }\end{array}$ & $\begin{array}{l}\text { verbas } \\
\text { You verb }\end{array}$ & $\begin{array}{c}\text { verbabis } \\
\text { You will verb }\end{array}$ \\
\hline \multirow{2}{*}{$\begin{array}{l}\text { With the first part telling you what the action is, the } \\
\text { second part telling you when, and the third part telling } \\
\text { you who. }\end{array}$} & $\begin{array}{l}\text { Third Person } \\
\text { He/She }\end{array}$ & $\begin{array}{l}\text { verbavit } \\
\text { He verbed }\end{array}$ & $\begin{array}{l}\text { verbat } \\
\text { He verbs }\end{array}$ & $\begin{array}{l}\text { verbabit } \\
\text { He will verb }\end{array}$ \\
\hline & \multicolumn{4}{|c|}{$\begin{array}{l}\text { While different verbs differ in their stems, these endings apply to } \\
\text { all verbs. }\end{array}$} \\
\hline
\end{tabular}

Figure 1. Grammar lesson slides for the grammar instruction condition. 
2007; Shook, 1994) as measured by a variety of recognition, recall, and grammaticality judgment tasks. Others have found no effect of TE on learning (Izumi, 2002; Leow, 1997, 2001; Leow, Egi, Nuevo, \& Tsai, 2003; Overstreet, 1998; Wong, 2003). These discrepancies are likely the result of study differences in learners' target and native languages, target type, complexity, amount of task-essential communication, density of target exposure, learner proficiency, treatment intensity, and the measures used to assess the noticing and learning of these forms.

Many TE studies have simply evaluated how well learners acquire the target forms, leaving to speculation learners' degree of attention to these forms (Han, Park, \& Combs, 2008; Leow et al., 2003). However, some studies have adopted methods such as retrospective verbal reports, note-taking (Izumi, 2002), or think-alouds (Alanen, 1995; Jourdenais et al., 1995; Leow, 2001; Leow et al., 2003; Overstreet, 1998) to try to measure the amount of noticing of the target forms. Retrospective verbal reports are problematic because the probability of forgetting restricts the claims that can be made regarding learners' attention to or awareness of the forms (Leow, 2007; Winke, 2013). Even online measures, such as note-taking and concurrent think-alouds, can be troublesome because one cannot be certain that failing to capture noticing in these types of tasks necessarily means that the learners did not notice the forms; as Winke (2013) describes, "at a lower level of processing, individuals may register the form but not be able to selfreport noticing" (p. 329). An important recent advance, therefore, is the inclusion of eye-movement recordings as a measure of attention with TE (Winke, 2013). In Winke's (2013) study, although enhancement of English passive forms neither significantly improved nor detracted from learners' performance in subsequent form correction and comprehension tasks, those exposed to the enhanced forms revisited these forms more often and fixated on them longer than those exposed to the unenhanced text. This provided evidence for the positive impact of enhancement at least in drawing learners' attention to nonsalient forms.

In the present study, we operationalize TE by means of boldfacing and color to make verbal inflectional cues more salient. This condition is therefore called verbal salience (VS). Following Winke (2013), we use eye-tracking to measure the visual attention to form that results from this condition and all other conditions of language exposure.

\section{Verb Pretraining (VP)}

Blocking is particularly potent whenever the cue to be learned is met in conjunction with other cues that have the same interpretation and have 
been learned previously or are more salient. One counter, therefore, is to ensure that, early in L2 experience, the cue is experienced on its own in situations in which it must be processed for successful interpretation. N. C. Ellis and Sagarra's (2010a, 2011) VP conditions tested the effects of this and demonstrated that once the cue has been consolidated into the processing system, it continues to contribute to processing in subsequent situations of potential cue competition. For the sake of continuity, replication, and comparison, therefore, we include the VP condition of N. C. Ellis and Sagarra (2011) here to investigate its mechanisms with eye-tracking and to compare its efficiency and operation with VG and VS conditions.

\section{Eye-Tracking as a Measure of Attention}

Second language acquisition research is increasingly recognizing eyetracking as a research tool (Roberts \& Siyanova-Chanturia, 2013; Winke, Godfroid, \& Gass, 2013). Eye-movement recordings provide a means toward capturing language learning attentional processes and allowing a direct, objective study of moment-by-moment processing decisions during natural, uninterrupted comprehension without the need to rely on participants' strategic or metalinguistic responses (Roberts \& SiyanovaChanturia, 2013, p. 214).

Kruschke, Kappenman, and Hetrick (2005) demonstrated that eyetracking could be used to inform the processes of blocking in associative learning. They showed that participants' eye gaze in the training phase of a blocking experiment (the equivalent of our Phase 2) was greater for the blocking cue than the blocked cue and that individual differences in this ratio covaried with covert indices of blocking in a subsequent testing phase $(r=.48)$ : Individuals who showed stronger overt gaze preferences in the learning phase tended to show stronger blocking.

N. C. Ellis et al. (2014) adopted eye-tracking to investigate the locus of learned attention effects in L2 acquisition for verb and adverb pretraining. Eye-tracking measures showed that prior experience with particular cue dimensions affected what participants overtly focused on during subsequent language processing; this overt focus, in turn, resulted in covert attentional biases in comprehension and in productive knowledge. A structural equation model showed that as participants' overt attention to verbs in Phase 2 increased, they displayed more covert attention to verb cues $(\beta=0.49)$ and less attention to adverb cues $(\beta=-0.32)$ in comprehension and greater knowledge of verb cues $(\beta=0.40)$ and less knowledge of adverb cues $(\beta=-0.06)$ in production (N. C. Ellis et. al, 2014, Figure 10). 


\section{Aims}

The current research therefore aimed to explore and compare the degree to which and the processes by which VG, VS, and VP methods of FonF might counteract learned attention effects when the learning of verb inflections is blocked by L2 learners' learned attention to adverbial cues.

In Experiment 1 we compared the behavioral effects of L1 Englishspeaking participants in a control condition (CC) with those in VG, VS, and VP conditions. The control condition and VP conditions allowed us to replicate N. C. Ellis and Sagarra (2011) with larger samples. The VG and VS conditions allowed us to compare the effects of these two FonF manipulations with VP.

In Experiment 2, we investigated the attentional processes of a subset of learners from Experiment 1. Eye-tracking data showed us the effects of these FonF manipulations on overt attention to the lexical and morphological cues during language processing, and we assessed in turn the effects of this attention to input on subsequent knowledge.

In Experiment 3, we investigated (a) the degree to which L1 speakers of Chinese (no verb tense morphology) are less than or equally able as L1 speakers of English (light morphology) to acquire inflectional cues from the same language experience in which adverb and verb cues were equally available, and (b) whether VG was equally effective in assisting learners in overcoming learned attentional biases. Again, in a subset of these learners, we investigated their attentional processes during processing to see how these determine later knowledge.

\section{EXPERIMENT 1}

Experiment 1 involved the L2 learning of a small number of Latin expressions and their translations by native English speakers. It investigated the learning of different types of cues for temporal reference, including adverbs (hodie "today," heri "yesterday," and cras "tomorrow") and verb inflections in three tenses and three persons (cogito "I think," cogitas "you think," cogitat "he/she thinks"; cogitavi "I thought," cogitavisti "you thought," cogitavit "he thought"; and cogitabo "I will think," cogitabis "you will think," cogitabit "he/she will think"). It determined if the acquisition of verb morphology is blocked in a CC in which the verb is always experienced along with another reliable adverbial indicator of event time. It then compared these levels of performance with those in three different explicit FonF conditions involving, respectively, VG, VS, and VP. 


\section{Participants}

Participants consisted of 320 individuals recruited from a major university in the United States $(n=308)$ or the local community $(n=12)$. They were volunteers, and they either participated as part of an undergraduate psychology course requirement or were compensated with 10 dollars for their time. Inclusion criteria required participants to be native English speakers who had not learned Latin or Italian previously. Participants could know Spanish but could not have been raised bilingually before the age of 6 years. Approximately two thirds of the participants had studied Spanish for more than 3 years, with a range of 1 to 15 years. They were randomly assigned to one of four conditions: $\mathrm{CC}, n=72$ (37 females and 35 males), age range $18-56$ years $(M=20.47$; median $=19) ;{ }^{1}$ VG, $n=101$ ( 67 females and 34 males), age range $17-49$ years $(M=20.23$; median $=20$ ); VS, $n=74$ (49 females and 25 males), age range 17-54 years $(M=19.59$; median $=19) ;^{2}$ and $\mathrm{VP}, n=73$ (42 females and 31 males), age range $18-24$ years $(M=19.22$; median $=19)$.

\section{Procedure}

The experiment was programmed in E-Prime (Schneider, Eschman, \& Zuccolotto, 2002). It took less than $1 \mathrm{hr}$ to complete. There were four phases: pretraining (Phase 1), sentence decoding (Phase 2), reception testing (Phase 3), and production testing (Phase 4). The procedure of the first three phases is schematized in Figure 2. The procedure for the VP and CC groups replicated N. C. Ellis and Sagarra (2011).

Phase 1. The VP participants engaged in a Phase 1 that involved training on verb inflections. On each trial they saw one of the past (cogitavi, cogitavisti, cogitavit) or present (cogito, cogitas, cogitat) inflected verbs and learned that each corresponded to either $X$ think $(s)$ or $X$ thought by clicking the appropriate alternative with the mouse. A correct choice returned the feedback "Correct" and an incorrect one "Incorrect-the meaning of [Latin word] is [English word]." Thus, throughout the 36 trials, each of the three persons of present and past tense were presented six times in random order. Because the future tense adverb and verb forms were only presented from Phase 2 onward, this allowed determination of whether training affected attention to cue dimensions rather than specific words.

Phase 1 for the VG participants involved a brief lesson on Latin verb tense morphology using the four slides shown in Figure 1. Although they could view each of the slides for an undetermined amount of time, 


\begin{tabular}{|c|c|c|c|}
\hline $\begin{array}{c}\text { Phase 1: Pretraining } \\
\text { (+ feedback) } \\
36 \text { randomized trials }\end{array}$ & $\begin{array}{l}\text { Phase 2: Sentence decoding } \\
\quad(+ \text { feedback }) \\
36(18 \times 2) \text { randomized trials }\end{array}$ & \multicolumn{2}{|c|}{$\begin{array}{c}\text { (-feedback) } \\
66 \text { randomized trials }\end{array}$} \\
\hline & Present & Stimulus & Semidiem \\
\hline Control group (CC) & Hodie cogito & Hodie & 3 \\
\hline \multirow[t]{2}{*}{ No pretraining } & Hodie cogitas & Heri & 1 \\
\hline & Hodie cogitat & Cras & 5 \\
\hline \multirow{5}{*}{$\begin{array}{l}\text { Verb grammar group } \\
\text { (VG) } \\
\text { Brief grammar lesson } \\
\text { (see Figure 1) }\end{array}$} & Cogito hodie & Cogito/as/at & 3 \\
\hline & Cogitas hodie & Cogitavi/visti/vit & 1 \\
\hline & Cogitat hodie & Cogitabo/bis/bit & 5 \\
\hline & & Hodie cogito/as/at & 3 \\
\hline & Past & Hodie cogitavi/visti/vit & 2 \\
\hline & Heri cogitavi & Hodie cogitabo/bis/bit & 4 \\
\hline Verb salience group (VS) & Heri cogitavisti & Heri cogito/as/at & 2 \\
\hline \multirow[t]{2}{*}{ No pretraining } & Heri cogitavit & Heri cogitavi/visti/vit & 1 \\
\hline & Cogitavi heri & Heri cogitabo/bis/bit & 3 \\
\hline & Cogitavisti heri & Cras cogito/as/at & 4 \\
\hline Verb pretraining group & Cogitavit heri & Cras cogitavi/visti/vit & 3 \\
\hline (VP) & & Cras cogitabo/bis/bit & 5 \\
\hline Cogito "I think" & Future & Cogito/as/at hodie & 3 \\
\hline Cogitas "you think" & Cras cogitabo & Cogitavi/visti/vit hodie & 2 \\
\hline Cogitat "X thinks" & Cras cogitabis & Cogitabo/bis/bit hodie & 4 \\
\hline Cogitavi "I thought" & Cras cogitabit & Cogito/as/at heri & 2 \\
\hline Cogitavisti "you & Cogitabo cras & Cogitavi/visti/vit heri & 1 \\
\hline thought" & Cogitabis cras & Cogitabo/bis/bit heri & 3 \\
\hline \multirow[t]{3}{*}{ Cogitavit " $\mathrm{X}$ thought" } & Cogitabit cras & Cogito/as/at cras & 4 \\
\hline & & Cogitavi/visti/vit cras & 3 \\
\hline & & Cogitabo/bis/bit cras & 5 \\
\hline
\end{tabular}

Figure 2. The design of Phases 1-3 of Experiment 1. 
the participants were not allowed to take notes and could not regress to previous slides. The mean time (and $S D$ ) in seconds spent looking at these slides was 22.8 (11.6) for Slide 1, 24.4 (10.6) for Slide 2, 16.8 (6.2) for Slide 3, and 33.8 (24.1) for Slide 4, giving a mean total instruction time of $1 \mathrm{~min} 38 \mathrm{~s}(S D=34.4 \mathrm{~s})$. There was no Phase 1 for the CC or VS participants.

Phase 2. In Phase 2, participants were exposed to 18 sentences (hodie cogito/as/at "today I think/you think/he/she thinks," cogito/as/at hodie "I think/you think/he/she thinks today," heri cogitavi/visti/vit "yesterday I thought/you thought/he/she thought," cogitavi/visti/vit heri "I thought/ you thought/he/she thought yesterday," cras cogitabo/bis/bit "tomorrow I will think/you will think/he/she will think," and cogitabo/bis/bit cras "I will think/you will think/he/she will think tomorrow") that appropriately combined the adverb with a verb (half were in adverb-verb word order and half were in verb-adverb order); they had to choose whether these sentences referred to the present, the past, or the future. Both word orders were used to counterbalance which cue was experienced first across sentences. Each of the 18 sentences was presented twice during this phase of the experiment. Feedback was given for both correct and incorrect choices. For correct answers, the word "correct" would appear on the screen, whereas for incorrect answers, participants would see the word "incorrect" accompanied by the correct answer (e.g. "Incorrect-[cogitavisti] is [past]").

The Phase 2 procedure was identical for the CC, VG, and VP groups. For VS participants only, the stimuli were textually enhanced so that the verbal inflections were highlighted in bold and red font to increase the salience of these items. Participants were not made aware of this beforehand and were given the same instructions for this task as were the other groups.

Phase 3. In this phase, participants were presented with all single-word items (verbs and adverbs) and all possible combinations of adverbs and verb tenses, a total of 12 single-word items and 54 two-word items (composed of 27 unique combinations), respectively (a grand total of 66 trials; see Figure 2). The two-word items were presented in two different word orders, counterbalancing which cue the participants would experience first. The presentation of all possible combinations meant that participants experienced sentences that were familiar to them from the previous task and also combinations in which the verb and adverb were incongruent in their time reference. Before the start of the task, participants were told that there would be both congruent and incongruent sentences. They were asked to judge their temporal reference on a 5-point scale by using their mouse to select the appropriate answer. The possible scale points were labeled 1 "past," 2 "both past and present," 
3 "present," 4 "both present and future," and 5 "future." Participants were told they could also choose 3 if they encountered an incongruent sentence with both past and future cues. For example, the participant could be presented with an incongruent sentence such as heri cogitabo "Yesterday I will think," for which the correct answer was 3; that is, the score was understood as the average of the items' tenses (past [1] + future [5] / $2=3$ ). The correct answer for each trial, which N. C. Ellis and Sagarra (2011) referred to as the semidiem, is shown in Figure 2. This task separately assessed the degree to which participants learned the adverb and verbal cues by determining the relative weight that learners put on adverbial and inflectional cues to time reference. For this reason, feedback was not provided.

Phase 4. In this phase, participants were asked to translate from English to Latin by typing in the Latin equivalents of several of the elements they had been exposed to. Nine unique items were given twice, for a total of 18 items. Three adverbs were given in isolation (yesterday, today, and tomorrow), three verbs were given in isolation ( $X$ thought, $X$ think(s), and $X$ will think), and three sentences were given in which the tense of the verb and the temporal adverb matched (yesterday $X$ thought, today $X$ think(s), and tomorrow $X$ will think). All the target productions in this phase had been experienced in Phase 2 of the experiment. This phase did not include feedback.

The logic behind the entire experiment follows that of previous studies of learned attention and blocking (N. C. Ellis et al., 2014; N. C. Ellis \& Sagarra, 2010a, 2010b, 2011). During Phase 2, regardless of condition, all participants experienced both the adverb and verbal cue together. If they paid equal attention to both cues during this phase, then their judgment during Phase 3 should have been equally affected by them, and in Phase 4 they should have done equally well in producing the adverbs and verbs with corresponding inflections. However, if they were biased toward one cue or the other, it is expected that their judgment in Phase 3 would be swayed toward the corresponding cue and that their productions in Phase 4 would also display this bias. Because those in the CC only saw the two cues together, their performance was expected to mirror how native speakers of English typically weigh these cues, which in N. C. Ellis and Sagarra $(2010 a, 2011)$ was characterized by the overshadowing of morphological cues by the more salient and reliable adverbial cues.

\section{Results}

Phase 2. The pretraining for the VP group gave them an accuracy advantage at the beginning of Phase 2 training: Mean performance in 
the first quarter of Phase 2 was $56 \%$ for the CC group, $61 \%$ for the VG group, $62 \%$ for the VS group, and $79 \%$ for the VP group. By the end of Phase 2, however, group performance levels had become more even: Mean performance in the final quarter of Phase 2 was $82 \%$ for the CC group, $81 \%$ for the VG group, $83 \%$ for the VS group, and $89 \%$ for the VP group. A one-way ANOVA on these final-quarter scores showed a marginally significant effect of group, $F(3,301)=2.88$, $p=.036$, and post hoc Tukey HSD tests demonstrated just one significant pairwise group difference: between the VP group and the VG group, $p=.03$.

Phase 3 (Perception Data). Participants in the four conditions differed in their cue use in Phase 3. Figure 3 illustrates the average group understanding of the temporal reference of each of the constructions of

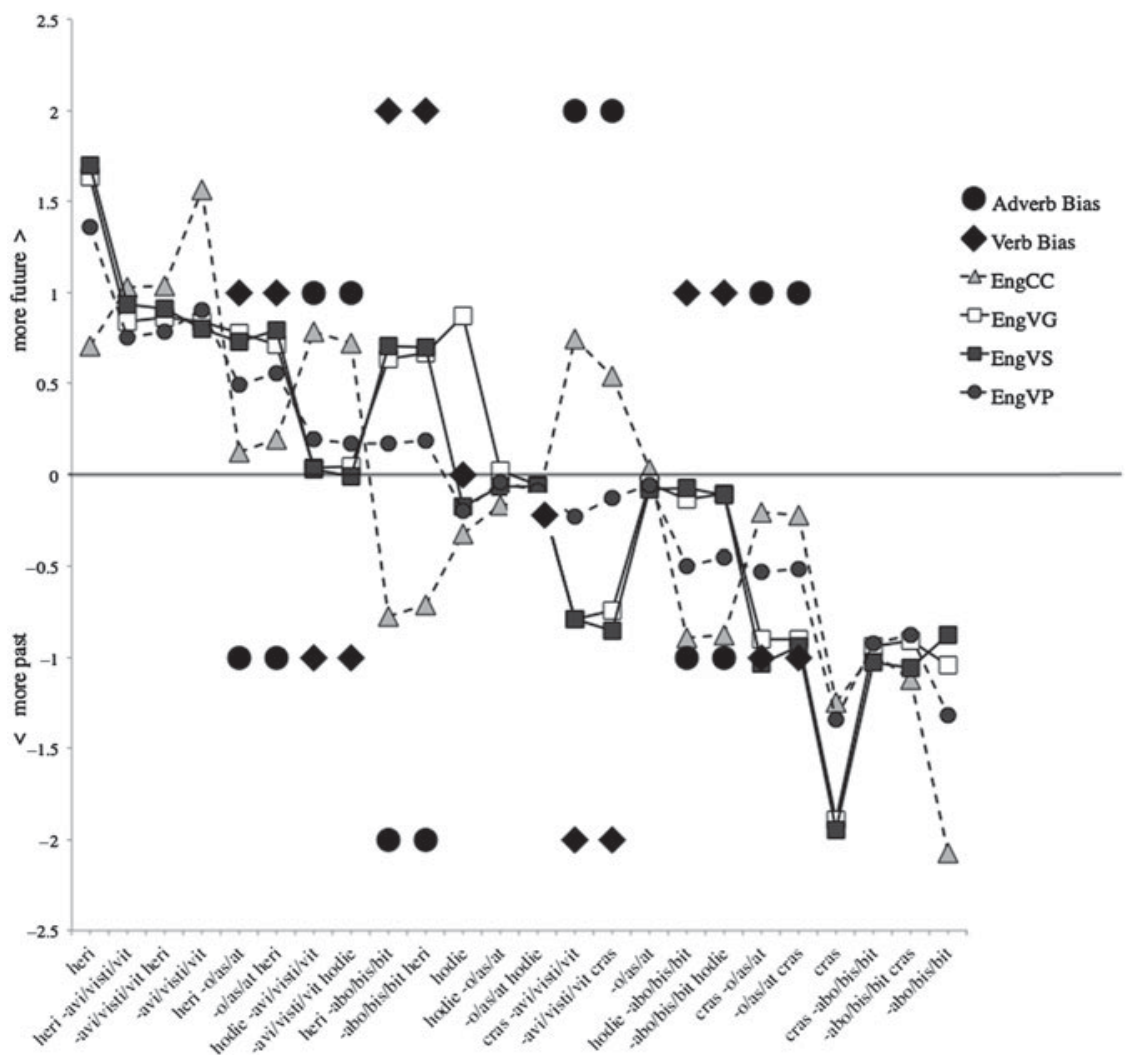

Figure 3. Mean deviations of Phase 3 temporal interpretations from the semidiem average. Bias symbols mark the deviation of the adverbial cues (circles) and verb inflection cues (diamonds) when these cues conflict. Eng = English. 
Phase 3 in terms of deviations from their semidiem average shown in the right column of Figure 2 (Phase 3). The constructions are ordered from past on the left to future on the right. For each string in which the two cues are in conflict, the large solid diamond shows the temporal information provided by the verb, and the large solid circle shows the temporal information provided by the adverb. In the sentence cogito heri "I think yesterday," for example, with a verb reference of 3 and an adverb reference of 1 , the respective deviations from the semidiem (2) are +1 and -1 ; for cogitabo heri "I will think yesterday," the verb reference is 5 , the adverb reference is 1 , and thus the relative deviations from the semidiem (3) are +2 and -2 .

Subject ratings are similarly plotted as deviations from the semidiem. Consider, for example, a participant rating heri cogitavi "Yesterday I thought." The semidiem in this case is (1 [Yesterday] + 1 [I thought]) / $2=1$. So a rating of 2 would be plotted as $(2$ [rating] -1 [semidiem] $)=+1$ (a unit deviation to the future), a rating of 1 would be plotted as (1 [rating] -1 [semidiem] $)=0$ (zero deviation), and so on. As a second example, consider a participant rating cras cogito "Tomorrow I think." The semidiem in this case is (5 [Tomorrow] +3 [I think]) $/ 2=4$. So a rating of 3 would be plotted as (3 [rating] -4 [semidiem]) $=-1$ (a unit deviation to the past; this is the score that someone who just interpreted the cogito would get), a rating of 4 would be plotted as (4 [rating] - 4 $[$ semidiem $])=0$ (a zero deviation indicating that the participant was balancing the information from both cues), a rating of 5 would be plotted as $(5$ [rating] -4 [semidiem $])=1$ (a unit deviation to the future; this is the score that someone who just interpreted the cras would get), and so on.

Figure 3 shows that in two-word strings of Phase 3 in which there is temporal information cued by both an adverb and a verb inflection, when these cues deviate, as in N. C. Ellis and Sagarra (2010b, 2011), CC learners tend to be more influenced by the adverb than the verb. However, the other groups are more sensitive to verb inflection, with VP participants showing a balance between the two cues, and VS and VG participants being more swayed by the verb.

These impressions are confirmed by four multiple regression analyses, one for each group, in which the dependent variable is the group mean temporal interpretation for each of the 54 two-word strings, and the independent variables are the interpretation cued by the adverb cue and the interpretation cued by the verb inflection. Differential cue use by each of the three groups, in standardized $\beta$ coefficients, is shown in Table 1.

Participants in the CC group, who had not been pretrained on either cue, relied more on the adverb cue $(\beta=0.97)$ than on the verb cue $(\beta=0.17)$. The confidence intervals (CIs) of the two coefficients are nonoverlapping. This performance may reflect the relative salience, 
Table 1. Regression analyses predicting mean temporal interpretation across the 54 two-word strings in Phase 3 as a function of adverbial and verb inflectional cue information in each of the four groups

\begin{tabular}{llcccc}
\hline Group & Cue & $\beta$ & $95 \%$ CI & Adjusted R & $F$ \\
\hline Control & Adverb & $.97^{* * *}$ & {$[0.91,1.02]$} & .96 & $654^{* * *}$ \\
& Verb & $.17^{* * *}$ & {$[0.12,0.22]$} & & \\
Verb grammar & Adverb & $.21^{* * *}$ & {$[0.18,0.23]$} & .99 & $2,528^{* * *}$ \\
& Verb & $.95^{* * *}$ & {$[0.92,1.00]$} & & \\
Verb salience & Adverb & $.14^{* * *}$ & {$[0.10,0.18]$} & .98 & $1,246^{* * *}$ \\
& Verb & $.98^{* * *}$ & {$[0.94,1.02]$} & & \\
Verb pretraining & Adverb & $.58^{* * *}$ & {$[0.52,0.63]$} & .96 & $699 * * *$ \\
& Verb & $.79^{* * *}$ & {$[0.74,0.84]$} & & \\
\hline
\end{tabular}

${ }^{* * *} p<.001$

simplicity, and reliability of the adverb cues compared to the verb inflections.

Against this baseline there are the effects of different types of explicit instruction. Verb grammar participants relied more on the verb cue $(\beta=0.95)$ than on the adverb cue $(\beta=0.21)$. Likewise, VS participants relied more on the verb cue $(\beta=0.98)$ than on the adverb cue $(\beta=0.14)$. Verb pretraining participants relied on both the verb $(\beta=0.79)$ and adverb $(\beta=0.58)$ cues. Comparing the $95 \%$ CIs for these coefficients across groups, relative adverb cue sensitivity was $\mathrm{CC}>\mathrm{VP}>\mathrm{VG}>\mathrm{VS}$; verb cue sensitivity was the reverse: $\mathrm{VS} \approx \mathrm{VG}>\mathrm{VP}>\mathrm{CC}$.

To determine whether these patterns are reliable across individual group members, we calculated the degree to which each individual's Phase 3 temporal rating on each construction correlated with the information provided by the verb cue and the information provided separately by the adverb cue. Pearson correlations show the degree to which each participant is biased by each cue. Figure 4, which plots each individual in the space defined in this way, shows that most CC individuals were predominantly influenced by the adverb cue, whereas most VS and VG participants were more influenced by the verb cue. Verb pretraining participants were more scattered: Most showed greater sensitivity to the verb, though there were some who lay close to the 45 degree diagonal, suggesting that they were more evenly affected by both cues.

The group means of these correlations are shown in Figure 5 (error bars represent $2 S E$ s) and the top panel of Table 2. Following Corey, Dunlap, and Burke (1998), when averaging or performing inferential statistics on the correlation coefficients, we first transformed the $r$ values to $z$ values, then performed the statistics, and then reverse transformed 


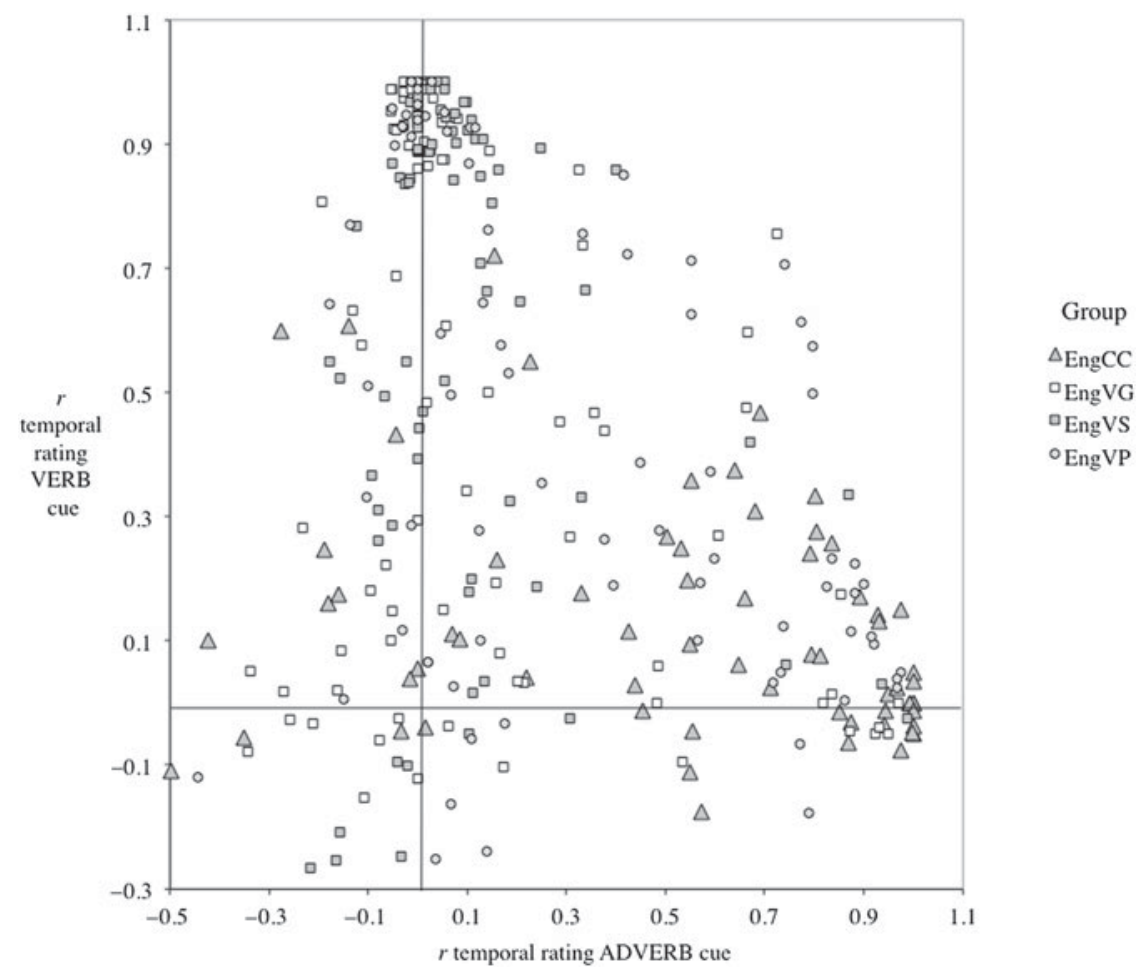

Figure 4. Sensitivity to adverbial and verbal inflectional cues to temporal reference for each participant. Eng = English.

to report the values. The group means of the individual correlations within each group are slightly different because of the different orders of steps of calculation, from the correlations of the group mean scores over the individuals, but the patterns are substantially the same. Control condition participants were more influenced by the adverb $(M=.73$, $95 \% \mathrm{CI}[.62, .83])$ than the verb $(M=.21,95 \% \mathrm{CI}[.14, .28])$. Verb grammar participants were influenced more by the verb $(M=.80,95 \% \mathrm{CI}[.71, .89])$ than the adverb $(M=.16,95 \%$ CI $[.10, .22])$; VS participants were also influenced more by the verb $(M=.70,95 \% \mathrm{CI}[.60, .80])$ than the adverb $(M=.13,95 \%$ CI $[.08, .19])$. Verb pretraining participants were influenced by both the verb $(M=.61,95 \% \mathrm{CI}[.52, .70])$ and the adverb $(M=.45,95 \%$ CI $[.37, .53])$.

An ANOVA (4 Groups $\times 2$ Cues, with subjects nested within groups) revealed a large and significant group by cue interaction, $F(3,325)=$ $32.93, p<.001, \eta^{2}=0.13$. To check that each of the FonF groups showed greater sensitivity to the verbal cue over the adverbial cue than did the controls, we performed individual ANOVAs ( 2 Groups $\times 2$ Cues) of each FonF group against the $\mathrm{CC}$ group. The group by cue interaction was 


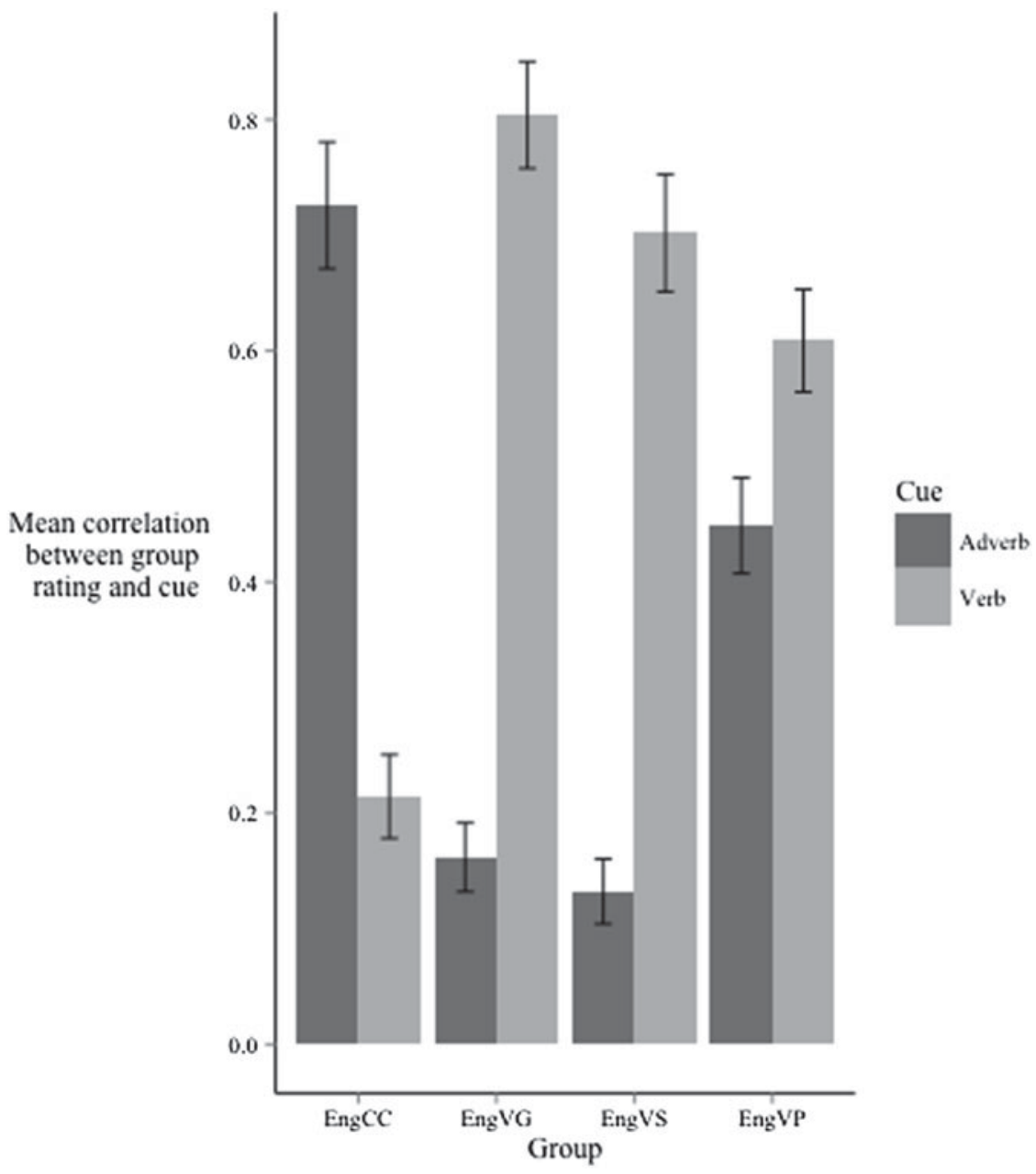

Figure 5. Group mean correlations between individual participants' Phase 3 sentence ratings and the information given by the corresponding adverb and verb cues. Error bars are 2 standard errors long. Eng = English .

significant for the VG group versus the CC group, $F(1,171)=77.07$, $p<.001, \eta^{2}=0.18$, and for the VS group versus the CC group, $F(1,146)=$ $66.31, p<.001, \eta^{2}=0.18$. For the VP group versus the CC group there was a main effect of cue, $F(1,150)=5.37, p=.022, \eta^{2}=0.02$, and a significant interaction of group and cue, $F(1,150)=24.94, p<.001$, $\eta^{2}=0.08$. All three FonF treatments therefore increased sensitivity to the verb cue; VP participants additionally maintained sensitivity to the adverb. 
Table 2. Mean participant performance of the four groups of Experiment 1

\begin{tabular}{|c|c|c|c|}
\hline Group & Cue & Mean & $95 \% \mathrm{CI}$ \\
\hline \multicolumn{4}{|c|}{ Correlations of Participant Rating with Cue across Strings of Phase 3} \\
\hline \multirow[t]{2}{*}{ Control } & Adverb & .73 & {$[.62, .83]$} \\
\hline & Verb & .21 & {$[.14, .29]$} \\
\hline \multirow[t]{2}{*}{ Verb grammar } & Adverb & .16 & {$[.10, .22]$} \\
\hline & Verb & .80 & {$[.71, .89]$} \\
\hline \multirow[t]{2}{*}{ Verb salience } & Adverb & .13 & {$[.08, .19]$} \\
\hline & Verb & .70 & {$[.60, .80]$} \\
\hline \multirow[t]{2}{*}{ Verb pretraining } & Adverb & .45 & {$[.37, .53]$} \\
\hline & Verb & .61 & {$[.52, .70]$} \\
\hline \multicolumn{4}{|c|}{ Accuracy of Production of Cue in Phase 4} \\
\hline \multirow[t]{2}{*}{ Control } & Adverb & .50 & {$[.43, .57]$} \\
\hline & Verb & .28 & {$[.22, .35]$} \\
\hline \multirow[t]{2}{*}{ Verb grammar } & Adverb & .29 & {$[.24, .34]$} \\
\hline & Verb & .36 & {$[.30, .42]$} \\
\hline \multirow[t]{2}{*}{ Verb salience } & Adverb & .31 & {$[.25, .38]$} \\
\hline & Verb & .39 & {$[.33, .46]$} \\
\hline \multirow[t]{2}{*}{ Verb pretraining } & Adverb & .47 & {$[.40, .55]$} \\
\hline & Verb & .52 & {$[.46, .58]$} \\
\hline
\end{tabular}

Phase 4 (Production Data). Each participant translated 18 items, of which 12 required adverb production and 12 verb production. The production data were scored following the procedure of N. C. Ellis and Sagarra (2011, pp. 602-603) and were expressed as proportion correct production for the adverb and verb separately.

The group means of these production scores are shown in Figure 6 and the bottom panel of Table 2. Control condition participants produced the adverb $(M=.50,95 \% \mathrm{CI}[0.43,0.57])$ more reliably than the verb $(M=.28,95 \%$ CI $[0.22,0.35])$. Verb grammar participants produced the verb $(M=.36,95 \%$ CI $[0.30,0.42])$ marginally more reliably than the adverb $(M=.29,95 \% \mathrm{CI}[0.24,0.34])$, as did VS participants: verb, $M=.39,95 \% \mathrm{CI}(0.33,0.46)$; adverb, $M=.31,95 \% \mathrm{CI}$ $(0.25,0.38)$. Verb pretraining participants accurately produced both verbs $(M=.52,95 \% \mathrm{CI}[0.46,0.58])$ and adverbs $(M=.47,95 \% \mathrm{CI}$ $[0.40,0.55])$.

An ANOVA (4 Groups $\times 2$ Cues, with subjects nested within groups) showed a significant interaction between group and cue, $F(3,325)=$ $12.08, p<.001, \eta^{2}=0.04$. Within-group comparison of cue use using Fisher's LSD showed that the CC group produced the adverb more reliably than the verb $(p<.001)$, whereas the VG, VS, and VP groups produced verbs and adverbs at similar levels (ns). 


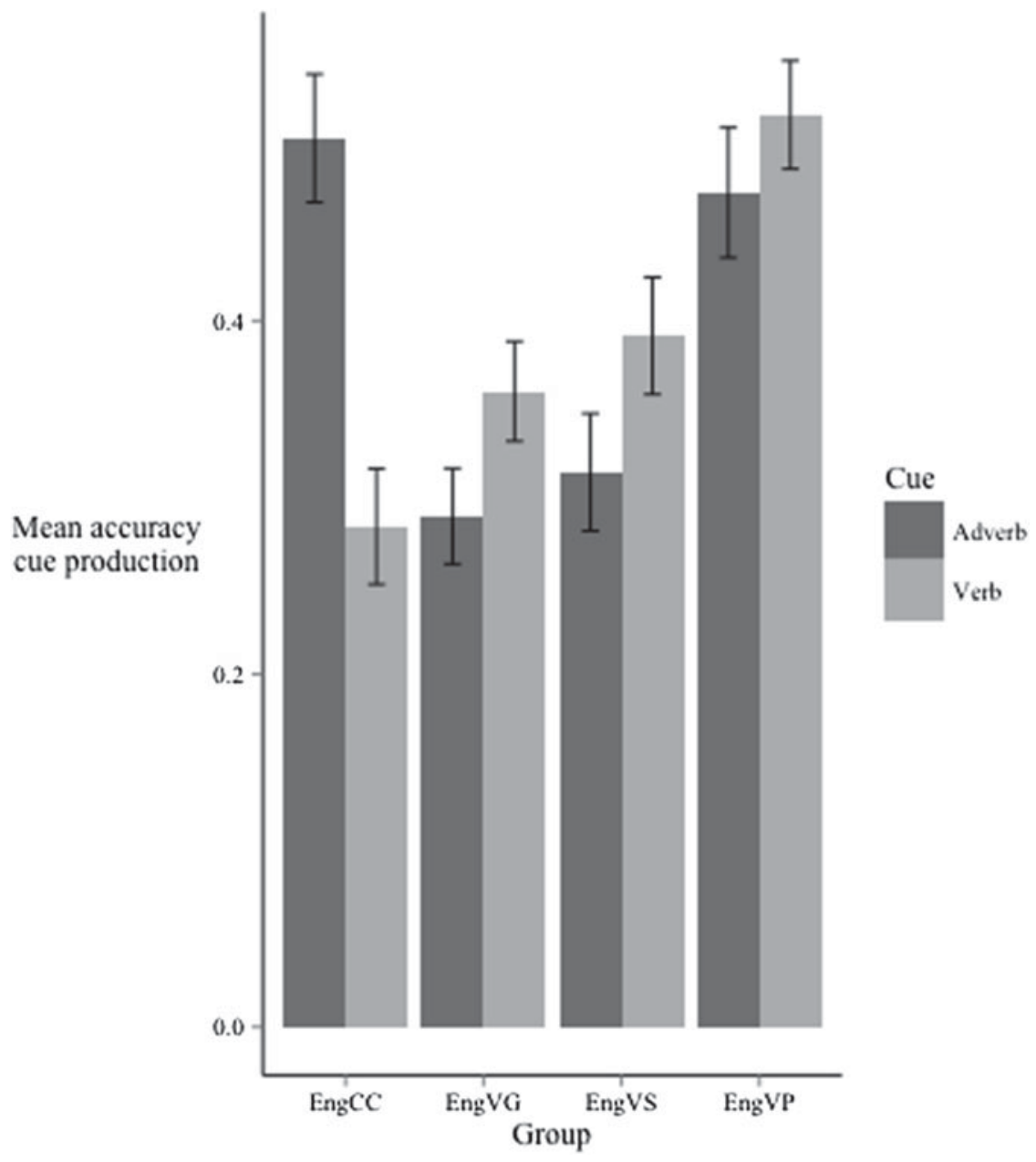

Figure 6. Group mean production scores for the adverb and verb cues. Error bars are 2 standard errors long. Eng = English.

\section{Discussion}

The results of Experiment 1 demonstrate that under CCs, adverbs were better learned than verb inflections. This was evidenced in both comprehension and production testing and replicates N. C. Ellis and Sagarra (2010a, 2011). We interpret these findings in terms of learner attention. First, the relative salience, simplicity, and reliability of adverb cues compared to verb inflections make them intrinsically more learnable. Second, adult language learners' prior knowledge of the use of adverb temporal references from their L1 results in long-term blocking. 
Pretraining on isolated verb cues (VP) reverses this bias. Verb pretraining participants used verbs more than adverbs in comprehension and were more able to produce verbs than were CC participants. Again, this replicates N. C. Ellis and Sagarra (2010a, 2011) and demonstrates learned attention effects in the short term of an experiment manipulating instructional sequence; prior learning of one cue affects learner attention such that, subsequently, learners attend more to that cue.

The two novel conditions in this experiment were VG and VS. Early focusing of attention on verbal morphology by means of less than 2 min of VG-a FonF that explained how tense and person were encoded-resulted in better verb comprehension and production than in both the CC and VP groups. Making the verbal morphology salient by means of TE during exposure to both cues in the sentences of Phase 2 improved later verb comprehension and production to similar levels as the VG group, which was again superior to both the $\mathrm{CC}$ and $\mathrm{VP}$ groups.

Thus all three FonF manipulations resulted in superior acquisition of verbal morphology. Of the three treatments, VP resulted in more balanced acquisition of both verbal and adverbial cues.

\section{EXPERIMENT 2}

To investigate how these different FonF manipulations affected attention to input during language processing, we used eye-tracking to record learners' overt attention to adverbs and verb inflections during Phase 2 in a subset of the previously described participants. In the introduction section, we described the use of this tool in L2 acquisition research more generally (Winke et al., 2013), in studying the processes of blocking in associative learning (Kruschke et al., 2005), and, more specifically still, in investigating the locus of learned attention effects in L2 acquisition under control conditions and following verb and adverb pretraining (N. C. Ellis et al., 2014).

\section{Participants}

Eye-tracking data were collected for a subset $(n=66)$ of the Experiment 1 participants: 18 participants in the CC group (seven females and 11 males), age range $18-22$ years $(M=19.28$; median $=19) ; 17$ in the VS group (nine females and eight males), age range 18-21 years $(M=19$; median = 19); 17 in the VG group (10 females and seven males), age range $20-22$ years $(M=19.88$; median $=20)$; and 18 in the VP group (12 females and six males), age range $18-21$ years $(M=18.94$; median $=19)$. 


\section{Procedure}

Eye-movement recordings were gathered using an ISCAN-ETL 400 eyeimaging system with a sampling rate of $60 \mathrm{~Hz}$. The eye-tracking cameras were mounted on headgear. Before the start of Phase 1 (or Phase 2 for the CC and VS participants), the participants' gaze was calibrated using a 6-point calibration sequence. This sequence was again repeated for all participants before starting Phase 3 . Eye-tracking equipment was not used to collect data during Phase 4 . Stimuli were presented in E-Prime and were positioned within a screen area of $640 \times 480$ pixels. In Phase 2 , the left stimulus (STIML) was centered at coordinates (x, y) 94, 99, and the right stimulus (STIMR) was positioned at coordinates 454, 99. For Phase 3, STIML and STIMR were positioned at 109, 108 and 505, 108, respectively. Participants' fixations were analyzed using ILAB (Version 3.6.4), an open-source program developed for the analysis of eye-movement recordings (Gitelman, 2002) through the MATLAB software platform (Version 7.12.0.635). For each condition, fixations were analyzed from $600 \mathrm{~ms}$ after the start of the Phase 2 and Phase 3 trials (coinciding with the end of the presentation of a fixation cross at the center of the screen) until the end of each trial (coinciding with participant response). Region of interest (ROI) analyses were calculated using two positions (left and right) at the uppermost part of the screen. Both ROIs had a height of 200 pixels and a width of 250 pixels; the ROI for STIML was centralized at 175, 103 pixels and the ROI for STIMR, at 465, 103 pixels. These relatively large ROIs reflect our simple setup, which involved merely a chin rest and forehead bar to stabilize the participant's head position. In some cases, for individual subjects it was necessary to edit coordinates for both ROIs to adjust for drift. Fixation analyses were run using the default ILAB fixation velocity/distance calculation parameters, with fixations determined according to degree of movement (horizontal 1.02 degrees; vertical 1.09 degrees) and a minimum duration of $100 \mathrm{~ms}$. Eye-movement analysis was done blind to stimulus content: The random order of stimulus presentation for each participant entailed that right and left fixation durations were assigned as verb and adverb fixation durations only in subsequent statistical analysis on the basis of trial number.

\section{Results}

Behavioral Data. Figure 7 confirms that the behavioral data of this subset of participants reflects the overall Experiment 1 patterns of comprehension in Phase 3 (left panel) and of production in Phase 4 (right panel). This is clear for Phase 3 and is generally the case for Phase 4, with the exception of the VS group, which here produces adverbs somewhat more reliably than in Experiment 1 (we do not know why). 

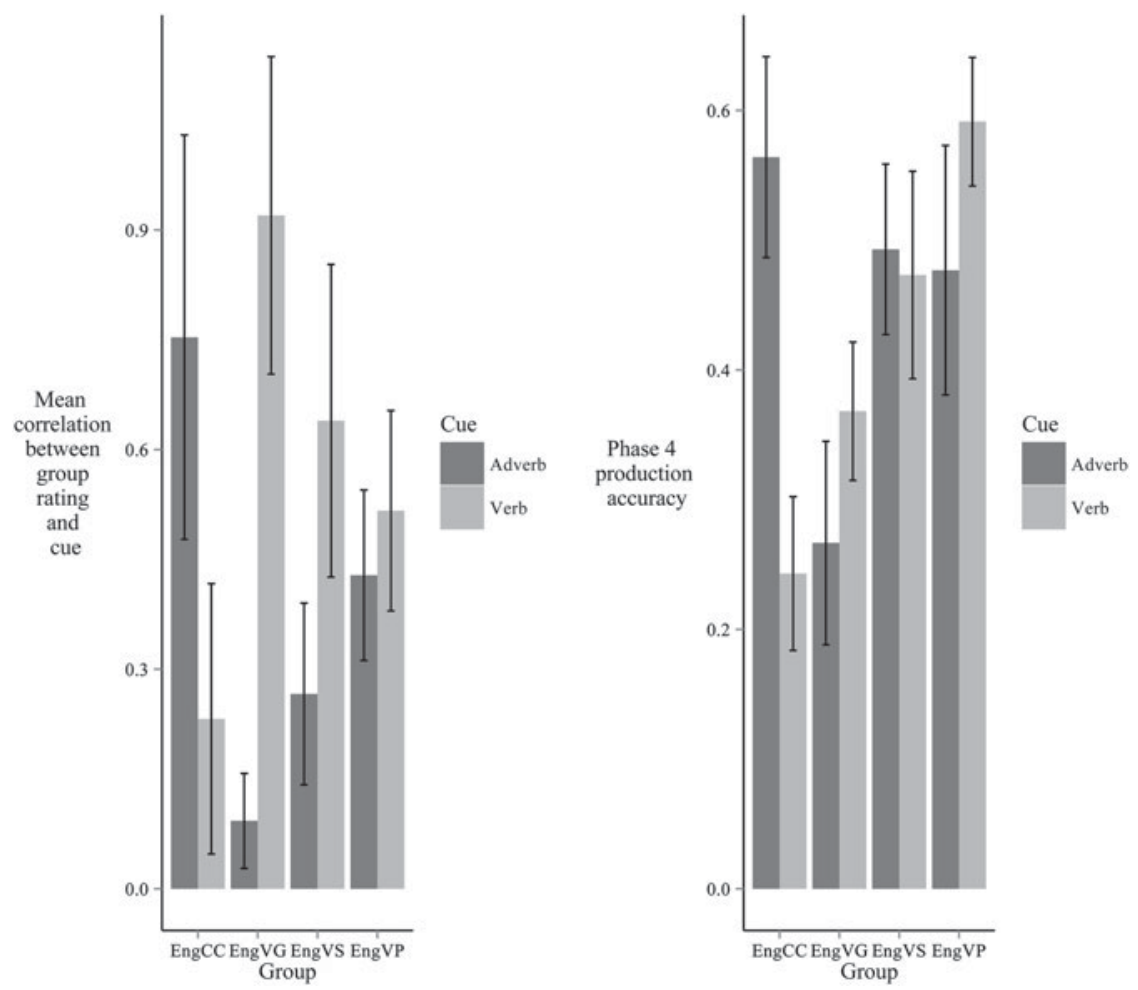

Figure 7. Experiment 2 group mean correlation (left) and production accuracy (right) for the adverb and verb cues. Error bars are 2 standard errors long. Eng = English .

Phase 2 Eye-Tracking Data. Figure 8 and Table 3 show the group mean fixation duration of these participants as they were studying the adverb and verb cues during exposure to the Latin sentences in Phase 2. It was this usage that led to the knowledge expressed in Figure 7. The left-hand panel of Figure 8 shows the total fixation duration on these cues. The right panel shows these data as the proportion of the total fixations on each trial (i.e., the relative amount of attention given to the verb or adverb). The pattern is quite clear. All groups looked at the verb more than the adverb, but the three explicit FonF groups did so much more than the CC group. Note that the verb stem plus inflections were overall more salient in terms of the number of letters than were the shorter adverbs.

An ANOVA on the proportion fixations ( 4 Groups $\times 2$ Cues, with subjects nested within groups) showed a significant effect of cue, $F(1,60)=128.5$, $p<.001, \eta^{2}=0.68$, and a significant group by cue interaction, $F(3,60)=4.59$ $p<.001, \eta^{2}=0.19$. To check that each of the FonF groups gave greater attention to the verbal cue over the adverbial cue than did the controls, we 

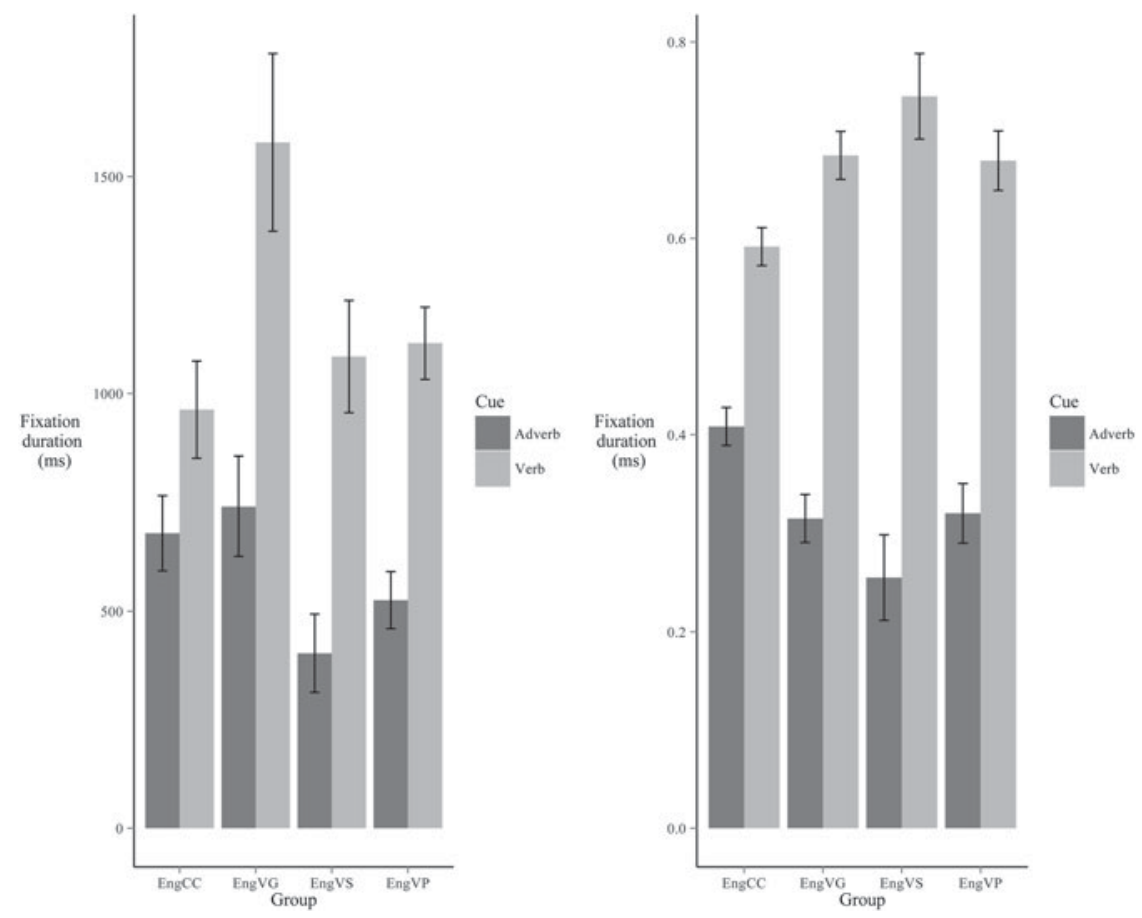

Figure 8. Mean group fixation duration (left) and proportion fixation duration (right) on the adverb and verb cues in exposure Phase 2. Error bars are 2 standard errors long. Eng = English.

performed individual ANOVAs ( 2 Groups $\times 2$ Cues) for each FonF group against the $\mathrm{CC}$ group. The group by cue interaction was significant for the VG group versus the CC group, $F(1,31)=9.11, p=.005, \eta^{2}=0.23$; this was also the case for the VS group versus the CC group, $F(1,32)=11.16, p=.002$, $\eta^{2}=0.26$, and for the VP group versus the CC group, $F(1,31)=6.31, p=.017$, $\eta^{2}=0.17$. All three FonF treatments therefore paid more attention than the $\mathrm{CC}$ group to the verb cue while processing these two-part stimuli.

Correlations for Phase 2 (Attention), Phase 3 (Comprehension), and Phase 4 (Production). Pearson correlations investigating the relations between attention in Phase 2, comprehension ability in Phase 3, and production ability in Phase 4 across all the participants and groups of Experiment 2 show that the proportion of fixation time spent on the adverb in Phase 2 correlates significantly with later adverbial bias in Phase $3(r=.55, p=.00)$ and with correct adverbial production in Phase $4(r=.26, p=.04)$. The proportion of fixation time spent on the verb in Phase 2 correlates significantly with later verb bias in Phase $3(r=.34, p=.01)$ and with correct verb production in Phase $4(r=.28, p=.03)$. 
Table 3. Mean participant fixations on the adverb and verb cues by the four groups of Experiment 2

\begin{tabular}{llrc}
\hline Group & \multicolumn{1}{c}{ Cue } & Mean & 95\% CI \\
\hline Mean Total Fixation Duration (ms) & & \\
Control & Adverb & 680 & {$[347,1,012]$} \\
& Verb & 963 & {$[532,1,394]$} \\
Verb grammar & Adverb & 741 & {$[300,1,182]$} \\
& Verb & 1,579 & {$[793,2,365]$} \\
Verb salience & Adverb & 403 & {$[56,750]$} \\
& Verb & 1,085 & {$[589,1,581]$} \\
Verb pretraining & Adverb & 526 & {$[274,778]$} \\
& Verb & 1,116 & {$[797,1,437]$} \\
Mean Proportion Fixation & Time & .59 & {$[.52, .67]$} \\
Control & Adverb & .41 & {$[.33, .48]$} \\
& Verb & .68 & {$[.59, .78]$} \\
Verb grammar & Adverb & .32 & {$[.22, .41]$} \\
& Verb & .74 & {$[.58, .91]$} \\
Verb salience & Adverb & .26 & {$[.09, .42]$} \\
Verb pretraining & Verb & .68 & {$[.56, .80]$} \\
& Adverb & .32 & {$[.20, .44]$} \\
\hline
\end{tabular}

Phase 2 Eye-Tracking over Trials. So how do these attentional biases change over experience of usage in Phase 2? Although the random order of stimuli was different for each participant, we can determine the degree to which the participants attended to the verb and adverb cues over trials. Figure 9 shows the total fixation duration on each cue by trial of experience in the three groups. It can be seen that CC participants initially spent more time looking at the verb, but interest in this cue waned over trials and more attention was paid to the adverbial cue. Participants in the three FonF conditions, however, maintained a steady attentional preference for the verb cue. These patterns are clearer in Figure 10, which plots the proportion of fixation time on each trial spent on the adverb and verb cues, respectively.

\section{Discussion}

The eye-tracking data showed how FonF treatments affected attention to cues in the input processing in Phase 2. Over the whole session, all participants looked relatively more at the verbs (i.e., verb stem + inflection) than they did at the shorter adverb. However, all FonF treatments (VG, VS, and VP) led to significantly more scrutiny of the verbs during Phase 2 processing than did the CC. The correlational analyses suggest 

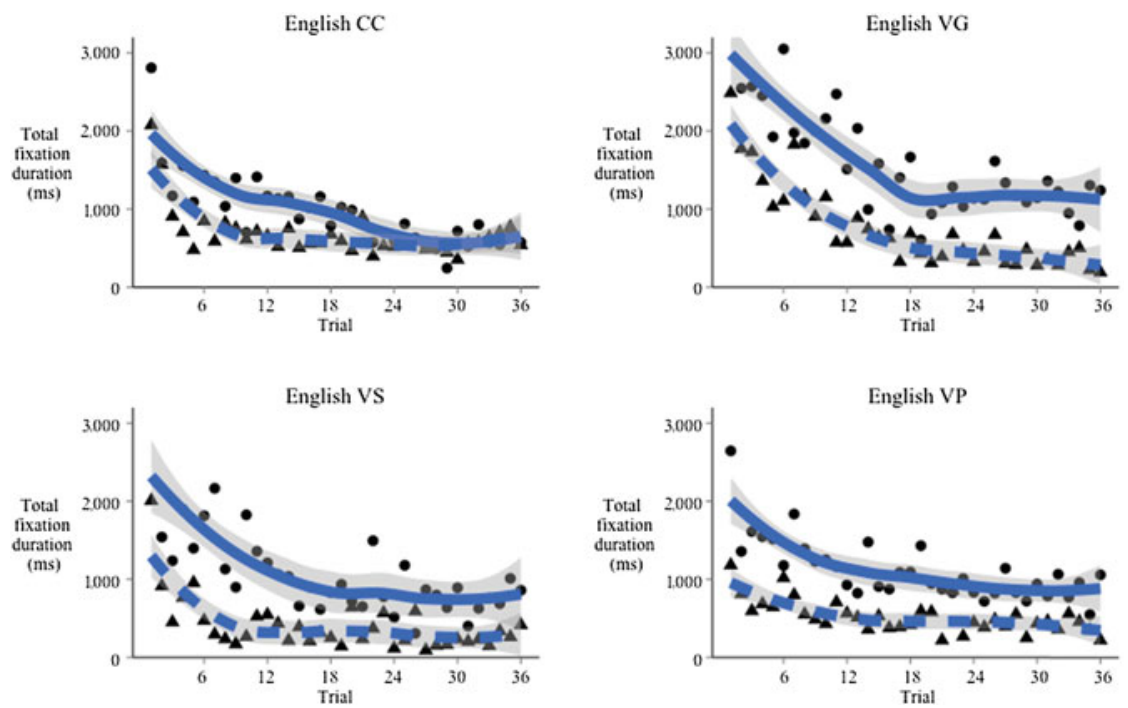

Figure 9. Mean fixation duration for each FonF group on the adverb and verb cues over trials (solid lines and circles = verb, and dotted lines and triangles $=$ adverb).

that it is the relative amount of time spent processing the verb and/or adverb cues in Phase 2 that determined cue usage in later comprehension and production. The trial-by-trial analyses showed how, in early exposure, CC participants fixated on both cues but fairly soon came to attend relatively more to the adverbs. Whether they could not fathom the verbal inflections or whether they simply came to rely more on the more reliable and salient adverbial cue we cannot tell. However, it is clear that, within about 20 trials of exposure, CC learners preferentially attended to adverbial cues. However, as seen in Figures 9 and 10, if learners had already been made aware of verbal cues (VP), or if their functions had already been explained (VG), then learners attended to them more from the outset, and they continued to focus more on these cues. From Figure 10, it is apparent that the bias increased over exposure in the VG group. Preferential attention to the verbs was also achieved in the VS group by making the verbal inflections more salient with TE during exposure to the language input.

\section{EXPERIMENT 3}

Blocking as a long-term attentional bias in language processing results from a lifetime of prior language usage. N. C. Ellis and Sagarra (2011) illustrated differential long-term language transfer effects whereby the nature of learners' L1 (+/- verb tense morphology) prejudiced the acquisition of 

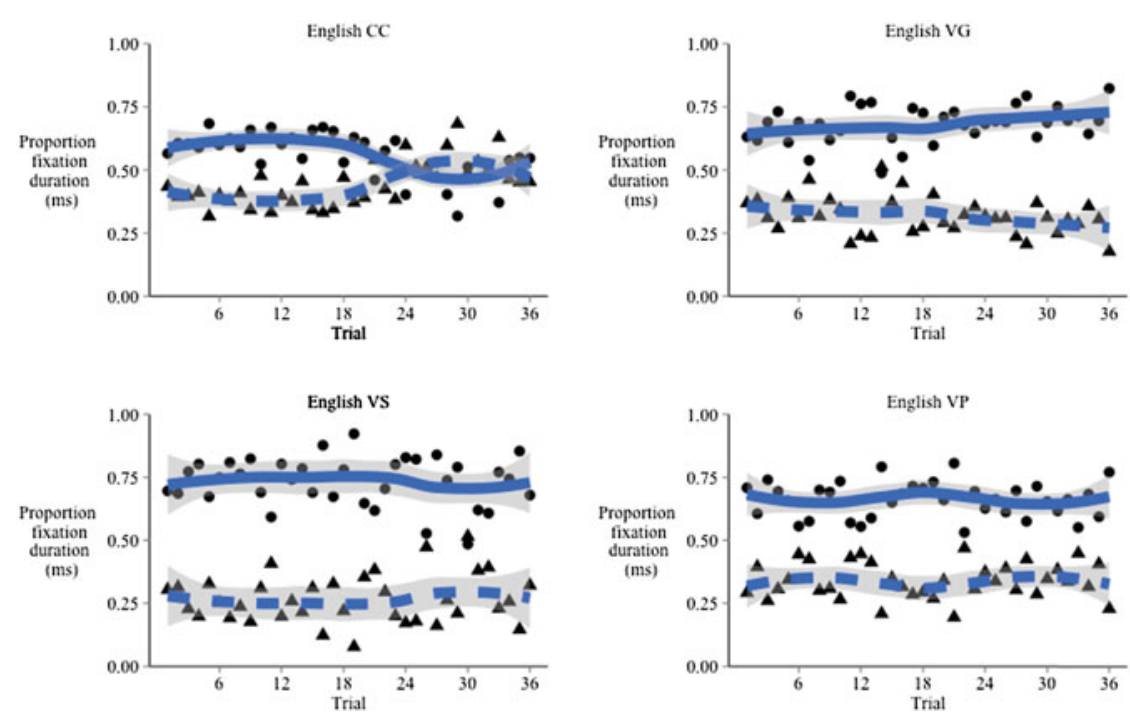

Figure 10. Mean proportion fixation for each FonF group on the adverb and verb cues over trials (solid lines and circles = verb, and dotted lines and triangles $=$ adverb).

morphological versus lexical cues to temporal reference using the same experimental paradigm as used here. First language speakers of Chinese (no tense morphology) were less able than L1 speakers of Spanish or Russian (rich morphology) to acquire inflectional cues from the same language experience in which adverbial and verbal cues were equally available (learned attention to tense morphology in standardized $\beta$ coefficients): Chinese $(\beta=-0.02)<$ English $(\beta=0.17)<$ Russian $(\beta=0.22)<$ Spanish $(\beta=0.41$; Ellis \& Sagarra, 2011, Table 4). However, it remains to be shown that these behavioral effects likewise reveal themselves in differential overt attention to cues during Phase 2 processing. Furthermore, it remains to be seen whether FonF can be equally effective in promoting the processing of L2 verbal inflections in native speakers of Chinese, whose L1 does not exhibit verb tense morphology (either free or bound) that corresponds to tense and in which "gender, plurality and tense are either indicated by lexical choice or not indicated at all" (Li \& Thompson, 1987, p. 825).

Experiment 3 therefore compares L1 Chinese learners' learning of verb morphology under $\mathrm{CC}$ and VG conditions.

\section{Participants and Procedure}

Chinese native speakers who had not learned Latin or Italian previously were recruited from a major university in the United States $(n=70)$ or 
the local community $(n=6)$. They were volunteers and either participated as part of an undergraduate psychology course requirement or were compensated with 10 dollars for their time. Note that all were bilingual with high-level English language proficiency sufficient to admit them to study in English. However, all had learned English as a L2 after the age of 5 years. A subset of the participants had previously studied Spanish $(\mathrm{CC}=3 ; \mathrm{VG}=2)$ but reported fewer than 3 years of instruction. Participants were randomly assigned to one of two conditions: CC, $n=44$ (30 females and 14 males), age range $18-35$ years $(M=23.09$; median $=22)$, and VG, $n=32$ (25 females and 7 males), age range $19-39$ years $(M=22.84$; median $=21$ ).

As in Experiment 2, eye-tracking data were collected for a small subset of this sample $(n=31)$. There were 15 participants in the CC (eight females and seven males), age range $18-35$ years $(M=23.82$; median $=23$ ), and 16 in the VG group (11 females and five males), age range $20-26$ years $(M=22.83$; median $=21.00)$.

The procedure was an exact replication of the CC and VG conditions of Experiment 1.

\section{Results}

\section{Behavioral Data from the Larger Sample}

Phase 3 (perception data). The multiple regression analyses of group mean temporal interpretation against the interpretation cued by adverb and by verb inflection revealed that Chinese $\mathrm{CC}$ participants relied more on the adverb cue, $\beta=0.95, p<.001,95 \% \mathrm{CI}[0.87,1.03]$, than on the verb cue, $\beta=0.09, p=.05,95 \% \mathrm{CI}[0.00,0.17]$. When we compare these figures with the Experiment 1 English CC participants (adverb cue, $\beta=0.97, p<.001 ;$ verb cue $\beta=0.17, p<.001)$, Chinese CC participants seem to be marginally less sensitive to the verbal cues than the English participants, with the English $\beta$ lying at the very top of the $95 \% \mathrm{CI}$ for the same Chinese coefficient. Chinese participants relied more on the verb cue, $\beta=0.93, p<.001,95 \%$ CI $[0.84,1.02]$, than on the adverb cue, $\beta=0.21$, $p<.001,95 \% \mathrm{CI}[0.12,0.30]$. Compared to the Chinese CC group, the VG group changed their relative attention to cues, similar to the Experiment 1 English VG participants (verb cue, $\beta=0.95, p<.001$; adverb cue, $\beta=0.21, p<.001)$.

As in Experiment 1, each participant's temporal rating responses for the strings in Phase 3 were correlated with the information provided by the verb cue and the information separately provided by the adverb cue to determine the degree to which each participant was biased by each cue type. Chinese CC participants were more influenced by the adverb $(M=.67,95 \% \mathrm{CI}[.55, .78])$ than the verb $(M=.05,95 \% \mathrm{CI}[.00, .11]$; 
compare these data with those of the English CC participants: adverb, $M=.73,95 \% \mathrm{CI}[.62, .83]$, and verb, $M=.21,95 \% \mathrm{CI}[.14, .28])$. In contrast, Chinese VG participants were more influenced by the verb $(M=.59,95 \%$ CI $[.45, .72])$ than the adverb $(M=.15,95 \%$ CI $[-.03, .26]$; compare these data with those of the English VG participants: verb, $M=.80,95 \%$ CI $[.71, .89]$, and adverb, $M=.16,95 \%$ CI [.10, .22]). A two-factor ANOVA comparing the Chinese CC group versus the Chinese VG group showed no overall effect of group, $F(1,75)=0.49, p=.490, \eta^{2}=0.00$; a main effect of cue, $F(1,75)=6.33, p=.014, \eta^{2}=0.04$; and a significant interaction of group and cue, $F(1,75)=41.88, p<.001, \eta^{2}=0.24$, again showing that the VG group increased sensitivity to the verb cue in L1 Chinese learners.

Phase 4 (production data). The production data were expressed as proportion correct production for the adverb and verb separately. Chinese CC participants produced the adverb $(M=.55,95 \%$ CI $[.45, .65])$ more reliably than the verb $(M=.23,95 \% \mathrm{CI}[.17, .29]$; compare these data with those of the English CC participants: adverb, $M=.50,95 \%$ CI $[.43, .57]$, and verb, $M=0.28,95 \%$ CI $[.22, .35])$. Chinese VG participants produced the verb $(M=.22,95 \%$ CI $[.16, .29])$ about as much as the adverb $(M=.23,95 \%$ CI $[.13, .33]$; compare these data with those of the English VG participants: verb, $M=.36,95 \%$ CI [.30, .42], and adverb, $M=.29,95 \%$ CI $[.24, .34])$. A two-factor ANOVA comparing the Chinese CC versus the VG group showed a significant effect of group, $F(1,75)=11.62, p=.001$, $\eta^{2}=0.09$; a main effect of cue, $F(1,75)=28.16, p<.001, \eta^{2}=0.12$; and a significant interaction of group and cue, $F(1,75)=18.53, p<.001$, $\eta^{2}=0.08$, showing that VG increased L1 Chinese learners' ability to produce verbal inflections, although perhaps to a lesser degree than for L1 English learners (the Chinese and English VG verb production CIs did not overlap).

\section{Eye-Tracking Data from the Subset}

Phase 2 eye-tracking data. Figure 11 shows the group mean fixation duration of the Chinese CC and VG participants as they were studying the adverb and verb cues during exposure to the Latin sentences in Phase 2. The data for English CC and VG participants from Experiment 2 are shown alongside for comparison. Verb grammar increased attention to the verb in both L1 groups.

An ANOVA (2 Groups [Chinese CC and Chinese VG] $\times 2$ Cues, with subjects nested within groups) showed a significant effect of cue, $F(1,29)=27.01, p<.001, \eta^{2}=0.13$, and a significant group by cue interaction, $F(1,29)=6.86, p=.014, \eta^{2}=0.04$.

Phase 2 eye-tracking over trials. Figure 12 shows the proportion fixation duration on each cue by trial of experience in the Chinese $\mathrm{CC}$ and Chinese VG groups; this information is placed under the English equivalent 


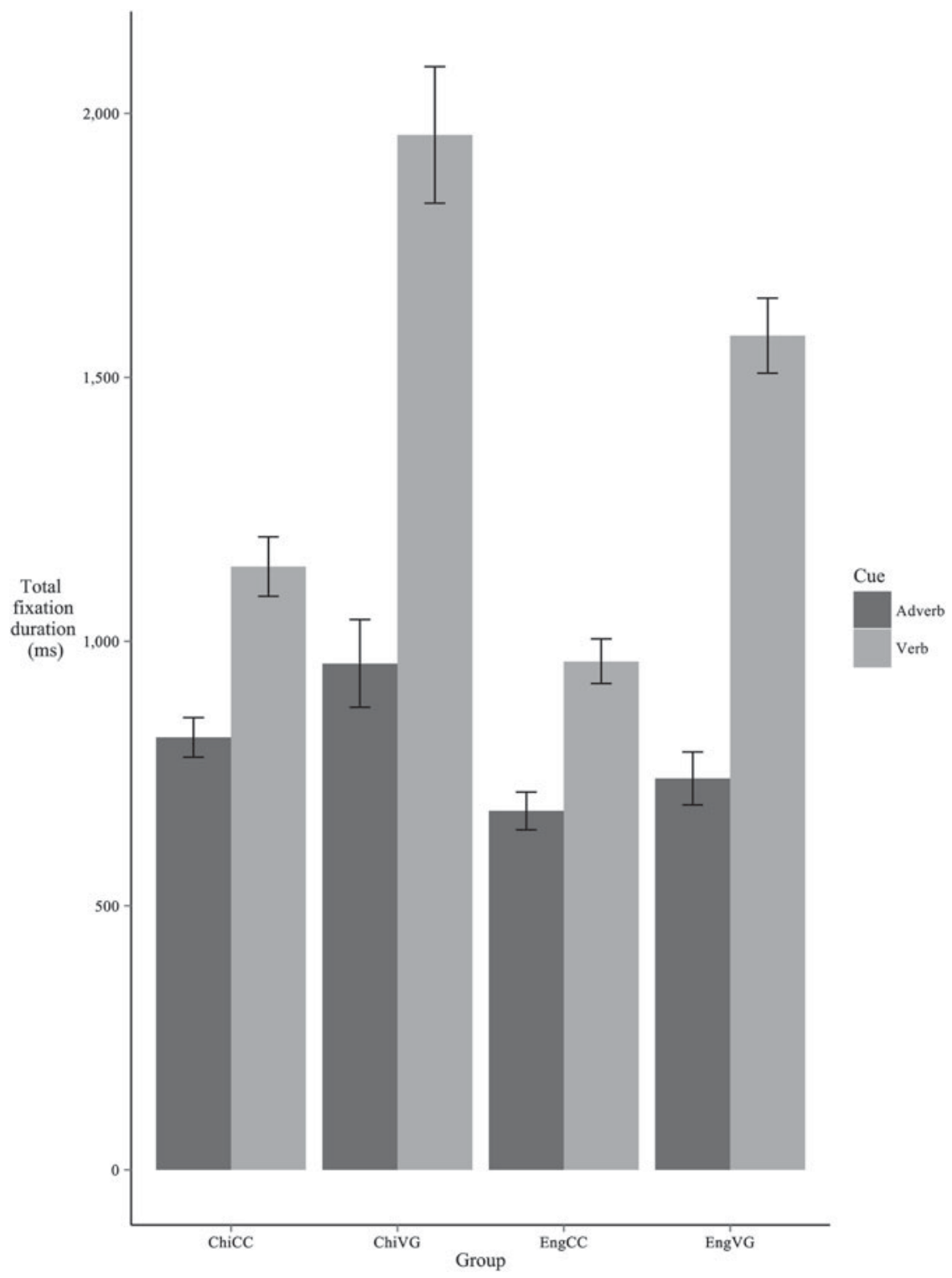

Figure 11. Mean group fixation duration on the adverb and verb cues in exposure Phase 2 for Chinese CC and VG participants alongside English CC and VG participants from Experiment 2. Error bars are 2 standard errors long. Chi $=$ Chinese; Eng $=$ English.

data from Experiment 2 for comparison. It can be seen that CC participants initially spent more time looking at the verb, but interest in this cue quickly waned over trials, and this happened earlier than it did for 

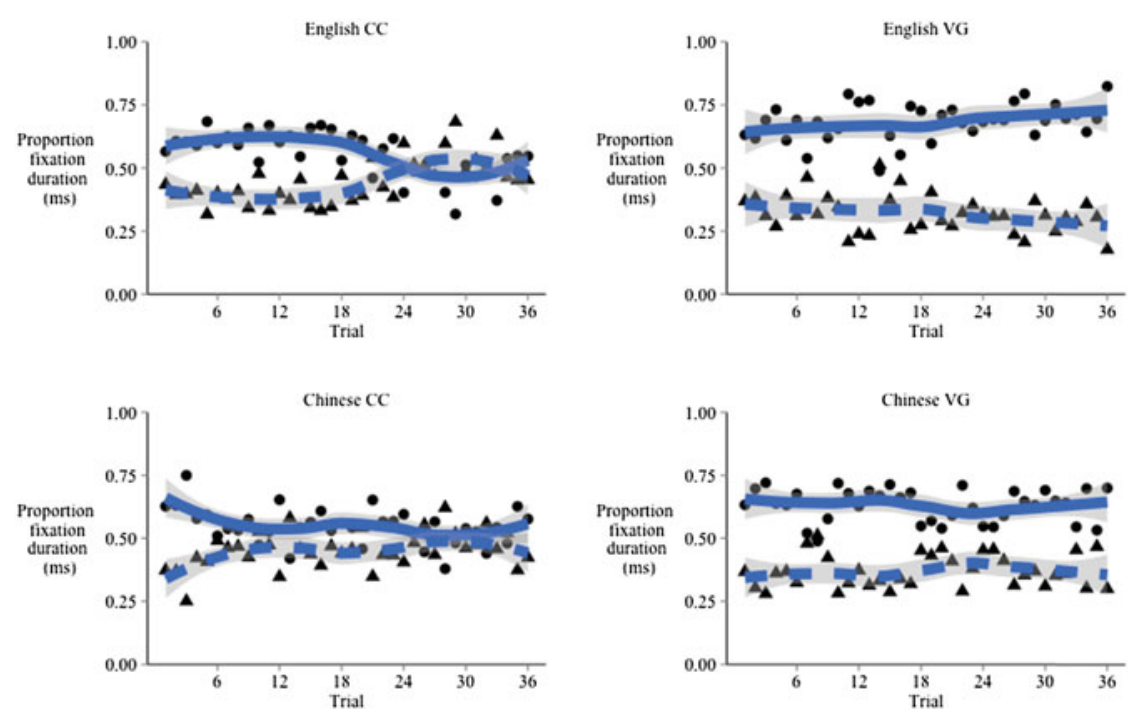

Figure 12. Mean proportion fixation for English (top) and Chinese (bottom) on the adverb and verb cues over trials (solid lines and circles = verb, and dotted lines and triangles = adverb).

the English CC participants. However, VG resulted in clear and steady attention to the verb cue across trials for the L1 Chinese participants just as it did for the L1 English participants.

\section{Discussion}

The behavioral data patterns for the L1 Chinese participants broadly followed those for the English ones. Chinese CC participants focused more on the adverbial cue than on the verbal cue in comprehension and production. They were marginally less sensitive to the verbal cues than was the L1 English group. Remember that all of these participants had learned English as a L2 to a high level, yet their L1 experience still has a marked enough effect to discriminate them from the English group in terms of sensitivity to verb morphology. Verb grammar increased the L1 Chinese learners' ability to comprehend and to produce verbal inflections, although, in absolute terms, perhaps to a lesser degree than for the L1 English learners. The eye-tracking data showed that Chinese CC learners rapidly lost interest in the verb cue across trials, more so than the English CC learners. Verb grammar FonF produced clear and steady attention to the verb cue across trials in the L1 Chinese participants just as in the L1 English participants. Although VG prompted the L1 
Chinese participants to attend to the verb more during input processing, they did not acquire as much from this experience as the L1 English participants.

\section{CONCLUSIONS}

These experiments lend further support to the idea that the limited attainment of adult second and foreign language learning follows general principles of associative learning and cognition. All three experiments demonstrated that under normal conditions (CC), adverbs were better learned than verb inflections. Replicating N. C. Ellis and Sagarra (2010a, 2011), this effect was evidenced in both comprehension and production testing. We interpret the better learning of the adverb cue under normal conditions in terms of learner attention: (a) The relative salience, simplicity, and reliability of adverb cues compared to verb inflections makes them intrinsically more learnable, and (b) adult language learners' prior knowledge of the use of adverb temporal references from their L1 results in long-term blocking - a learned attention effect. Pretraining on isolated verb cues (VP) reverses this bias. Verb pretraining participants used verbal morphology more than adverbs in comprehension and were more able to produce inflections. Again, this replicates N. C. Ellis and Sagarra (2010a, 2011) and demonstrates learned attention effects in the short term of an experiment manipulating instructional sequence: Prior learning of one cue affects learner attention such that learners subsequently attend more to that cue.

Two other FonF manipulations similarly resulted in superior acquisition of verbal morphology. Early focusing of attention on verbal morphology by means of a short grammar lesson, which explained how tense and person were encoded, resulted in better verb comprehension and production than no intervention (CC) or VP. Likewise, making the verbal morphology salient by means of TE during exposure to input led to superior verb comprehension and production than no intervention (CC) and VP.

Of the three treatments, VP resulted in more balanced acquisition of both verbal and adverbial cues. We believe that this is because, having learned to use the morphology, participants were next able to consider the role of adverbs, too. This finding parallels others demonstrating that, in the early stages of acquisition from a problem space comprising multiple cues to interpretation, participants typically focus on one cue at a time, exploring its utility and moving on to others later, one by one, as they reduce the error of estimation (Cheng \& Holyoak, 1995; MacWhinney, 1987; Matessa \& Anderson, 2000; McDonald, 1986). Verb salience learners were introduced to the verbal cues during the exposure phase but still had to sort out how they function. Verb grammar 
learners were first provided with declarative statements about their function but still had to put this knowledge to use during Phase 2. For these reasons, both VS and VG participants remained highly focused on the morphological cues.

In our study, L1 Chinese learners were especially insensitive to verbal morphology, less so than the L1 English group (as in N. C. Ellis \& Sagarra, 2011). Nevertheless, VG increased L1 Chinese learners' ability to comprehend and to produce verbal inflections, albeit in absolute terms, to a lesser degree than in L1 English learners. The eye-tracking data showed that Chinese CC learners rapidly lost interest in the verb cue across trials, more so than the English CC learners. In contrast, VG FonF produced clear and steady attention to the verb cue across trials in the L1 Chinese participants just as in the L1 English participants. Although VG prompted the L1 Chinese participants to attend to the verb more during input processing, they did not acquire as much from this experience as the L1 English participants. Thus, first, learned attention makes FonF necessary for successful L2 acquisition of low salience, low contingency, or redundant cues, and, second, it qualifies the rate of acquisition of these forms from subsequent experience of input.

Although, in the present experiments, the three different FonF treatments were broadly equally effective in focusing learners' attention in subsequent input processing and in affecting the rate of acquisition from this experience, we do not believe that this will necessarily be true for all linguistic constructions. As the recasts literature shows, different forms will require different levels of explicitness and explanation (Long, 2006; Spada \& Tomita, 2010). Additionally, as recent research by Tolentino and Tokowicz (2014) highlights, L1-L2 similarity along with the type of instructional method will also play a role in the learning of L2 morphosyntax. They found that in the case of dissimilar L1-L2 morphosyntactic features that are common to both languages but differ in the way they are represented (e.g., noun phrase definiteness in English and in Swedish), input enhancement was effective in improving learners' performance in subsequent posttests. However, in the case of features unique to the L2, input enhancement along with a metalinguistic explanation proved to be more beneficial.

Eye-tracking elucidated the attentional processes whereby the different types of FonF instruction affected attention to morphological cues in the input processing in Phase 2. All FonF treatments (VG, VS, and VP) led to significantly more scrutiny of the verbs during Phase 2 processing than in the $\mathrm{CC}$. The correlational analyses showed that the relative amount of time spent attending to the verb and/or adverb cues during input processing was positively related to cue usage in later comprehension and production. In early trials of experience, CC participants fixated on both cues but soon came to preferentially attend to adverbial cues. However, if the functions of verb inflections have 
already been explained (VG), if the verbal inflections were made more salient with TE during exposure (VS), or if participants were pretrained on verbal cues in nonredundant situations (VP), then learners attended to verbal morphology more from the outset and continued to focus more on these cues over trials of experience, with this bias increasing over time in the VG group.

N. C. Ellis (2005) reviewed aspects of the explicit-implicit interface whereby explicit FonF instruction might encourage subsequent use of a cue in processing:

Once consolidated into the construction, it is this new cue to interpretation of the input whose strengths are incremented on each subsequent processing episode. The cue does not have to be repeatedly noticed thereafter; once consolidated, mere use in processing for meaning is enough for implicit tallying. A natural corollary is that if explicit knowledge is to be effective, it must be provided before relevant input that exemplifies it. (p. 324)

Thus, FonF instruction attempts to guide attention to cues over repeated episodes of the processing of usage.

In terms of the psychological interface between explicit knowledge and processing, the behavioral data in our experiments demonstrate that FonF indeed causes learning to occur, and the eye-tracking data show that the different FonF treatments achieve this because there is greater overt attention on the verbal morphological cues on each experience of usage. Does this overt attention reflect explicit or implicit learning? Although we believe fixations reflect attention, we do not equate them with noticing or awareness and, without additional data that tap conscious awareness, we cannot say how it functions in this context. Eye movements can reflect conscious control, and we suspect that this is what is happening in early trials. On the other hand, eye movements in fluent reading are unconscious and automatically guided behaviors. The fixation times across trials shown in Figure 9 look very much like classical learning curves, and it is plausible that automatization and proceduralization is happening over usage experience (DeKeyser, 2001, 2007; Segalowitz, 2010). Perhaps by the end of Phase 2, attention to these cues is automatic. Whatever tallying that is taking place is surely implicit. These questions warrant future research with introspective and neuroimaging techniques. Nevertheless, the current research demonstrates the effects of FonF on trial-by-trial retuning of attention.

In terms of the educational interface between explicit knowledge and processing, these findings broadly confirm the mechanisms suggested by Terrell (1991) regarding EGI to increase the salience of inflections and other commonly ignored features by pointing them out and explaining 
their structure and then by providing meaningful input that contains many instances of the same grammatical meaning-form relationship. In terms of the dynamics of the interface, the new cue must be integrated into the processing of these instances. If successfully achieved, the strength of the new cue will increase with each subsequent processing episode.

\section{Received 11 October 2014}

\section{NOTES}

1. Although this age range appears to be large, there was only one participant of age 56 . 2. Again, only one participant was responsible for the large age range.

\section{REFERENCES}

Alanen, R. (1995). Input enhancement and rule presentation in second language acquisition. In R. Schmidt (Ed.), Attention and awareness in foreign language learning (pp. 259-302). Honolulu, HI: University of Hawai'i Press.

Bardovi-Harlig, K. (1992). The use of adverbials and natural order in the development of temporal expression. IRAL-International Review of Applied Linguistics in Language Teaching, 30(4), 299-320.

Bardovi-Harlig, K. (2000). Tense and aspect in second language acquisition: Form, meaning, and use. Oxford, UK: Blackwell.

Benati, A. (2013). The input processing theory in second language acquisition. In M. d. P. García Mayo, M. J. Gutierrez Mangado, M. Martínez Adrián, F. Myles, J. Rothman, \& B. VanPatten (Eds.), Contemporary approaches to second language acquisition (pp. 93-110). Amsterdam, the Netherlands: Benjamins.

Cheng, P. W., \& Holyoak, K. J. (1995). Adaptive systems as intuitive statisticians: Causality, contingency, and prediction. In J.-A. Meyer \& H. Roitblat (Eds.), Comparative approaches to cognition (pp. 271-302). Cambridge, MA: MIT Press.

Cho, M. Y. (2010). The effects of input enhancement and written recall on noticing and acquisition. Innovation in Language Learning and Teaching, 4, 71-87.

Clahsen, H., \& Felser, C. (2006). Grammatical processing in language learners. Applied Psycholinguistics, 27, 3-42.

Corey, D. M., Dunlap, W. P., \& Burke, M. J. (1998). Averaging correlations: Expected values and bias in combined Pearson $r$ s and Fisher's $z$ transformations. Journal of General Psychology, 125, 245-261.

DeKeyser, R. (2001). Automaticity and automatization. In P. Robinson (Ed.), Cognition and second language acquisition (pp. 125-151). Cambridge, UK: Cambridge University Press.

DeKeyser, R. (Ed.). (2007). Practice in a second language: Perspectives from applied linguistics and cognitive psychology. Cambridge, UK: Cambridge University Press.

Doughty, C., \& Williams, J. (Eds.). (1998). Focus on form in classroom second language acquisition. New York, NY: Cambridge University Press.

Ellis, N. C. (1993). Rules and instances in foreign language learning: Interactions of explicit and implicit knowledge. European Journal of Cognitive Psychology, 5, 289-318.

Ellis, N. C. (Ed.). (1994). Implicit and explicit learning of languages. San Diego, CA: Academic Press.

Ellis, N. C. (2002). Frequency effects in language processing: A review with implications for theories of implicit and explicit language acquisition. Studies in Second Language Acquisition, 24, 143-188.

Ellis, N. C. (2005). At the interface: Dynamic interactions of explicit and implicit language knowledge. Studies in Second Language Acquisition, 27, 305-352.

Ellis, N. C. (2006a). The associative-cognitive CREED. In B. V. Patten \& J. Williams (Eds.), Theories in second language acquisition: An introduction (pp. 77-96). Mahwah, NJ: Erlbaum. 
Ellis, N. C. (2006b). Selective attention and transfer phenomena in SLA: Contingency, cue competition, salience, interference, overshadowing, blocking, and perceptual learning. Applied Linguistics, 27, 1-31.

Ellis, N. C., Hafeez, K., Martin, K. I., Chen, L., Boland, J., \& Sagarra, N. (2014). An eye-tracking study of learned attention in second language acquisition. Applied Psycholinguistics, $35,547-579$.

Ellis, N. C., \& Sagarra, N. (2010a). The bounds of adult language acquisition: Blocking and learned attention. Studies in Second Language Acquisition, 32, 553-580.

Ellis, N. C., \& Sagarra, N. (2010b). Learned attention effects in L2 temporal reference: The first hour and the next eight semesters. Language Learning, 60(Suppl. 2), 85-108.

Ellis, N. C., \& Sagarra, N. (2011). Learned attention in adult language acquisition: A replication and generalization study and meta-analysis. Studies in Second Language Acquisition, $33,589-624$.

Ellis, R. (2006). Current issues in the teaching of grammar: An SLA perspective. TESOL Quarterly, 40, 83-107.

Ellis, R. (2008). Explicit form-focused instruction and second language acquisition. In B. Spolsky \& F. M. Hult (Eds.), The handbook of educational linguistics (pp. 437-455). Oxford, UK: Blackwell.

Ellis, R. (2012). Language teaching research and language pedagogy. Oxford, UK: WileyBlackwell.

Gitelman, D. R. (2002). ILAB: A program for post experimental eye movement analysis. Behavioral Research Methods, Instruments and Computers, 34, 605-612.

Goldschneider, J. M., \& DeKeyser, R. (2001). Explaining the "natural order of L2 morpheme acquisition" in English: A meta-analysis of multiple determinants. Language Learning, 51, 1-50.

Han, Z.-H., Park, E. S., \& Combs, C. (2008). Textual enhancement of input: Issues and possibilities. Applied Linguistics, 29, 597-618.

Izumi, S. (2002). Output, input enhancement, and the noticing hypothesis: An experimental study on ESL relativization. Studies in Second Language Acquisition, 24, 541-577.

Jourdenais, R., Ota, M., Stauffer, S., Boyson, B., \& Doughty, C. (1995). Does textual enhancement promote noticing? A think-aloud protocol analysis. In R. Schmidt (Ed.), Attention and awareness in foreign language learning (pp. 182-209.). Honolulu, HI: University of Hawai'i Press.

Kamin, L. J. (1969). Predictability, surprise, attention, and conditioning. In B. A. Campbell \& R. M. Church (Eds.), Punishment and aversive behavior (pp. 276-296). New York, NY: Appleton-Century-Crofts.

Klein, W. (1998). The contribution of second language acquisition research. Language Learning, 48, 527-550.

Krashen, S. D. (1985). The input hypothesis: Issues and implications. London, UK: Longman.

Krashen, S. D., \& Terrell, T. (1983). The natural approach: Language acquisition in the classroom. Oxford, UK: Pergamon Press.

Kruschke, J. K. (2006, June). Learned attention. Paper presented at the Fifth International Conference on Development and Learning, Indiana University, Bloomington.

Kruschke, J. K., \& Blair, N. J. (2000). Blocking and backward blocking involve learned inattention. Psychonomic Bulletin \& Review, 7, 636-645.

Kruschke, J. K., Kappenman, E. S., \& Hetrick, W. P. (2005). Eye gaze and individual differences consistent with learned attention in associative blocking and highlighting. Journal of Experimental Psychology: Learning, Memory, and Cognition, 31, 830-845.

Lee, J. F. (2002). The incidental acquisition of Spanish future morphology through reading in a second language. Studies in Second Language Acquisition, 24, 55-80.

Lee, S.-K. (2007). Effects of textual enhancement and topic familiarity on Korean EFL students' reading comprehension and learning of passive form. Language Learning, $57,87-118$.

Leow, R. P. (1997). The effects of input enhancement and text length on adult L2 readers' comprehension and intake in second language acquisition. Applied Language Learning, $8,151-182$.

Leow, R. P. (2001). Do learners notice enhanced forms while interacting with the L2? An online and offline study of the role of written input enhancement in L2 reading. Hispania, 84, 496-509. 
Leow, R. P. (2007). Input in the L2 classroom: An attentional perspective on receptive practice. In R. K. DeKeyser (Ed.), Practice in a second language. Cambridge, UK: Cambridge University Press.

Leow, R. P., Egi, T., Nuevo, A. M., \& Tsai, Y.-C. (2003). The roles of textual enhancement and type of linguistic item in adult L2 learners' comprehension and intake. Applied Language Learning, 13, 93-108.

Li, C. N., \& Thompson, S. A. (1987). Chinese. In B. Comrie (Ed.), The world's major languages (pp. 811-833). New York, NY: Oxford University Press.

Lightbown, P. M. (2008). Transfer appropriate processing in classroom second language acquisition. In Z.-H. Han (Ed.), Understanding second language process (pp. 27-44). Clevedon, UK: Multilingual Matters.

Long, M. H. (1991). Focus on form: A design feature in language teaching methodology. In K. de Bot, R. Ginsberg, \& C. Kramsch (Eds.), Foreign language research in cross-cultural perspective (pp. 39-52). Amsterdam, the Netherlands: Benjamins.

Long, M. H. (2006). Problems in SLA. Mahwah, NJ: Erlbaum.

Mackintosh, N. J. (1975). A theory of attention: Variations in the associability of stimuli with reinforcement. Psychological Review, 82, 276-298.

MacWhinney, B. (1987). The competition model. In B. MacWhinney (Ed.), Mechanisms of language acquisition (pp. 249-308). Hillsdale, NJ: Erlbaum.

MacWhinney, B. (2001). The competition model: The input, the context, and the brain. In P. Robinson (Ed.), Cognition and second language instruction (pp. 69-90). New York, NY: Cambridge University Press.

MacWhinney, B., \& Bates, E. (1989). The crosslinguistic study of sentence processing. Cambridge, UK: Cambridge University Press.

MacWhinney, B., Bates, E., \& Kliegl, R. (1984). Cue validity and sentence interpretation in English, German, and Italian. Journal of Verbal Learning and Verbal Behavior, 23, 127-150.

Matessa, M., \& Anderson, J. R. (2000). Modeling focused learning in role assignment. Language and Cognitive Processes, 15, 263-292.

MATLAB (Version 7.12.0.635) [Computer software]. Natick, MA: MathWorks.

McDonald, J. L. (1986). The development of sentence comprehension strategies in English and Dutch. Journal of Experimental Child Psychology, 41, 317-335.

Meisel, J. (1987). Reference to past events and actions in the development of natural second language acquisition. In C. Pfaff (Ed.), First and second language acquisition (pp. 206-224). New York, NY: Newbury House.

Norris, J., \& Ortega, L. (2000). Effectiveness of L2 instruction: A research synthesis and quantitative meta-analysis. Language Learning, 50, 417-528.

Noyau, C., Klein, W., \& Dietrich, R. (1995). Acquisition of temporality in a second language. Amsterdam, the Netherlands: Benjamins.

Overstreet, M. (1998). Text enhancement and content familiarity: The focus of learner attention. Spanish Applied Linguistics, 2, 229-258.

Rebuschat, P. (Ed.). (in press). Implicit and explicit learning of language. Amsterdam, the Netherlands: Benjamins.

Rescorla, R. A., \& Wagner, A. R. (1972). A theory of Pavlovian conditioning: Variations in the effectiveness of reinforcement and nonreinforcement. In A. H. Black \& W. F. Prokasy (Eds.), Classical conditioning II: Current theory and research (pp. 64-99). New York, NY: Appleton-Century-Crofts.

Roberts, L., \& Siyanova-Chanturia, A. (2013). Using eye-tracking to investigate topics in L2 acquisition and L2 processing. Studies in Second Language Acquisition, 35, 213-235.

Schmidt, R. (1984). The strengths and limitations of acquisition: A case study of an untutored language learner. Language, Learning, and Communication, 3, 1-16.

Schmidt, R. (1990). The role of consciousness in second language learning. Applied Linguistics, 11, 129-158.

Schmidt, R. (1993). Awareness and second language acquisition. Annual Review of Applied Linguistics, 13, 206-226.

Schmidt, R. (2001). Attention. In P. Robinson (Ed.), Cognition and second language instruction (pp. 3-32). Cambridge, UK: Cambridge University Press.

Schneider, W., Eschman, A., \& Zuccolotto, A. (2002). E-Prime user's guide. Pittsburgh, PA: Psychology Software Tools. 
Segalowitz, N. (2010). The cognitive bases of second language fluency. New York, NY: Routledge.

Shanks, D. R. (1995). The psychology of associative learning. New York, NY: Cambridge University Press.

Sharwood Smith, M. (1993). Input enhancement in instructed SLA: Theoretical bases. Studies in Second Language Acquisition, 15, 165-179.

Shook, D. J. (1994). FL/L2 reading, grammatical information, and the input to intake phenomenon. Applied Language Learning, 5, 57-93.

Spada, N. (1997). Form-focused instruction and second language acquisition: A review of classroom and laboratory research. Language Teaching Research, 30, 73-87.

Spada, N., \& Tomita, Y. (2010). Interactions between type of instruction and type of language feature: A meta-analysis. Language Learning, 60, 1-46.

Terrell, T. (1991). The role of grammar instruction in a communicative approach. Modern Language Journal, 75, 52-63.

Tolentino, L. C., \& Tokowicz, N. (2014). Cross-language similarity modulates effectiveness of second language grammar instruction. Language Learning, 64, 279-309.

VanPatten, B. (1996). Input processing and grammar instruction in second language acquisition. New York, NY: Ablex.

VanPatten, B. (2006). Input processing. In B. VanPatten \& J. Williams (Eds.), Theories in second language acquisition: An introduction (pp. 115-136). Mahwah, NJ: Erlbaum.

Wills, A. J. (2005). New directions in human associative learning. Mahwah, NJ: Erlbaum.

Winke, P. M. (2013). The effects of input enhancement on grammar learning and comprehension. Studies in Second Language Acquisition, 35, 323-352.

Winke, P. M., Godfroid, A., \& Gass, S. M. (2013). Introduction to the special issue. Studies in Second Language Acquisition, 35, 205-212.

Wong, W. (2003). Textual enhancement and simplified input effects on L2 comprehension and acquisition of non-meaningful grammatical form. Applied Language Learning, 13, $109-132$. 